\title{
Recent Developments in Chitosan-Based Micro/Nanofibers for Sustainable Food Packaging, Smart Textiles, Cosmeceuticals, and Biomedical Applications
}

\author{
Nguyen D. Tien ${ }^{1} \mathbb{D}$, Ståle Petter Lyngstadaas ${ }^{1}$, João F. Mano ${ }^{2} \mathbb{D}$, Jonathan James Blaker ${ }^{1,3, * \mathbb{C}}$ and \\ Håvard J. Haugen $1, *$ (D) \\ 1 Department of Biomaterials, Institute of Clinical Dentistry, University of Oslo, 0317 Oslo, Norway; \\ d.t.nguyen@odont.uio.no (N.D.T.); spl@odont.uio.no (S.P.L.) \\ 2 CICECO-Aveiro Institute of Materials, Department of Chemistry, University of Aveiro, \\ 3810-193 Aveiro, Portugal; jmano@ua.pt \\ 3 Department of Materials and Henry Royce Institute, The University of Manchester, Manchester M13 9PL, UK \\ * Correspondence: jonny.blaker@manchester.ac.uk (J.J.B.); h.j.haugen@odont.uio.no (H.J.H.)
}

check for updates

Citation: Tien, N.D.; Lyngstadaas, S.P.; Mano, J.F.; Blaker, J.J.; Haugen, H.J. Recent Developments in

Chitosan-Based Micro/Nanofibers for Sustainable Food Packaging, Smart Textiles, Cosmeceuticals, and Biomedical Applications. Molecules 2021, 26, 2683. https://doi.org/ $10.3390 /$ molecules 26092683

Academic Editor: Cédric Delattre

Received: 10 March 2021

Accepted: 1 May 2021

Published: 3 May 2021

Publisher's Note: MDPI stays neutral with regard to jurisdictional claims in published maps and institutional affiliations.

Copyright: (c) 2021 by the authors. Licensee MDPI, Basel, Switzerland. This article is an open access article distributed under the terms and conditions of the Creative Commons Attribution (CC BY) license (https:// creativecommons.org/licenses/by/ $4.0 /)$.

\begin{abstract}
Chitosan has many useful intrinsic properties (e.g., non-toxicity, antibacterial properties, and biodegradability) and can be processed into high-surface-area nanofiber constructs for a broad range of sustainable research and commercial applications. These nanofibers can be further functionalized with bioactive agents. In the food industry, for example, edible films can be formed from chitosan-based composite fibers filled with nanoparticles, exhibiting excellent antioxidant and antimicrobial properties for a variety of products. Processing 'pure' chitosan into nanofibers can be challenging due to its cationic nature and high crystallinity; therefore, chitosan is often modified or blended with other materials to improve its processability and tailor its performance to specific needs. Chitosan can be blended with a variety of natural and synthetic polymers and processed into fibers while maintaining many of its intrinsic properties that are important for textile, cosmeceutical, and biomedical applications. The abundance of amine groups in the chemical structure of chitosan allows for facile modification (e.g., into soluble derivatives) and the binding of negatively charged domains. In particular, high-surface-area chitosan nanofibers are effective in binding negatively charged biomolecules. Recent developments of chitosan-based nanofibers with biological activities for various applications in biomedical, food packaging, and textiles are discussed herein.
\end{abstract}

Keywords: chitosan nanofibers; sustainable food packaging; advanced textiles; biofunctionalized materials; wound care; skin graft substitute; dermal regeneration

\section{Introduction}

\subsection{Preparation and Properties of Chitosan}

Chitosan is presently one of the most attractive, sustainable biopolymers in use due to its availability and remarkable intrinsic properties, such as its digestibility, bacteriostatic and anti-inflammatory effects, biocompatibility, and biodegradability [1-3]. Chitosan is derived from chitin, which is extracted from crustacean shells (e.g., from crabs, lobsters, shrimps, or prawns) and mushrooms [4] through several processing methods involving demineralization and deproteination. The chitin is then converted to chitosan through a partial or full deacetylation process [5]. The production route and chemical structure of chitosan are described in Figure $1 \mathrm{~A}$.

Chitosan has a rigid D-glucosamine repeat unit, which consists of two monomers: $\beta$-(1-4)-2-acetamino-2-deoxy- $\beta$-D-glucose ( $N$-acetyl-D-glucosamine) and $\beta-(1-4)$-2-deoxy$\beta$-D-glucopyranose ( $N$-amino-D-glucosamine) [6]. There are three functional groups in each repeating unit of chitosan: primary hydroxyl, secondary hydroxyl, and amine groups. Chemical modifications commonly target the amino groups to obtain desired properties 
and distinctive biological functions [7,8]. The degree of deacetylation (DDA) of chitosan is generally defined as the $\mathrm{N}$-amino-D-glucosamine/ $\mathrm{N}$-acetyl-D-glucosamine ratio, an important indicator that determines the distinction between chitin and chitosan, thus leading to the noteworthy properties of chitosan. When the DDA is higher than $50 \%$, the polymer is commonly called chitosan, becomes soluble in aqueous acidic media and is considered a cationic biopolymer due to protonation of the amino groups [9]. In terms of biological activity, a high DDA results in better compatibility and increases the interaction between chitosan and cells [10-12]. However, a low DDA induces an increase in the secretion of osteoprotegerin and sclerostin (SOST) relative to a high DDA [13]. Moreover, the combination of a high DDA and a high molecular weight $\left(M_{\mathrm{W}}\right)$ has been shown to increase secretion of vascular endothelial growth factor (VEGF) and interleukin 6 (IL-6) but reduce secretion of osteopontin (OPN) compared to chitosan with a similar DDA but a lower $M_{\mathrm{w}}$. Manipulation of DDA and $M_{\mathrm{w}}$ therefore offers a strategy to tailor chitosan to specific industrial or biomedical requirements [14,15]. However, acetyl groups are removed during the deacetylation process, causing changes in $M_{\mathrm{w}}$ that must be taken into consideration when designing chitosan-based materials. Similarly, the $M_{\mathrm{w}}$ of chitosan (commonly ranging from 300 to 1 million) can affect its antibacterial properties [16,17], by which it impairs bacterial physiological activities at the cellular level [18]. Molecules with lower $M_{\mathrm{w}}$ degrade faster than those with higher $M_{\mathrm{w}}$, and molecules with low $M_{\mathrm{w}}$ and low DDA are more reactive as substrates but more vulnerable to biological degradation and chemical decay [19].

\section{(A) Production of chitosan}

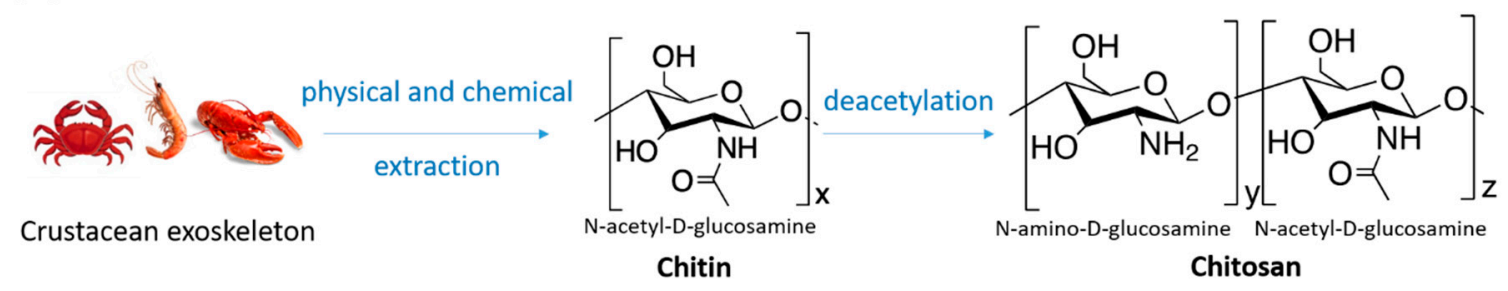

(B) Electrospinning

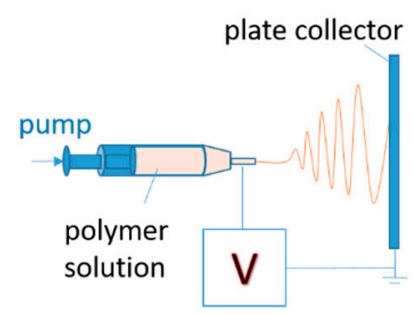

\section{(C) Solution blow spinning}

\section{drum collector}

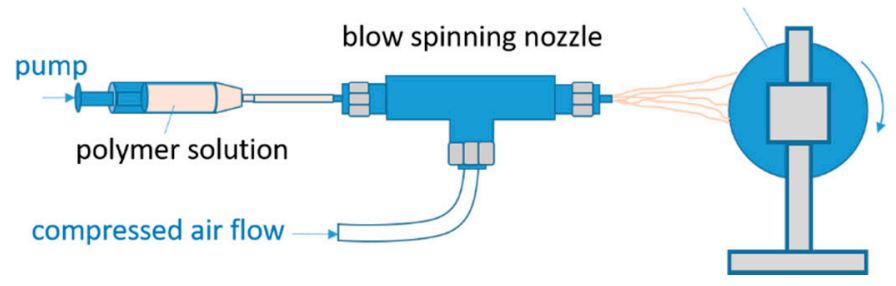

Figure 1. (A) The production of chitosan: Chitosan is made by deacetylation of chitin extracted from crustacean exoskeleton. Chitosan nanofibers are commonly fabricated by (B) electrospinning or (C) solution blow spinning, usually from chitosan dissolved in acetic acid. The principle of electrospinning is the induction of a liquid jet from a syringe nozzle using a high voltage, while solution blow spinning uses a high-pressure inert gas as a driving force. The solvent evaporates at the nozzle, and the polymer chains are stretched and travel the tip-to-collector distance, where the solidified nanofibers accumulate on the collectors.

\subsection{Fabrication of Chitosan-Based Micro/Nanofibers}

Among the different physical forms of chitosan (e.g., powder, film, foam, and gel), chitosan-based nanofibers have drawn much attention due to their unique characteristics, such as their large surface-area-to-volume ratio and good mechanical strength when blended with other polymers [17]. Like most natural polymers, chitosan-based nanofibers can be made to retain biodegradable and biocompatible properties, which are of interest for applications in areas such as agriculture, packaging, or biomedicine [20]. 
Due to its versatility, electrospinning currently remains the most commonly used technique for the production of submicron-sized fibers since its emergence in the 1970s [21,22]. The principle of this technique is the formation of a liquid jet induced by an electrical field (Figure 1B). After solvent evaporation, a solid fiber is formed and deposited on the collector. However, electrospinning has a number of drawbacks. First, it requires hazardous operating conditions, such as high voltages and the use of toxic volatile organic solvents [23-26]. Furthermore, the effects of environmental conditions (ambient temperature and humidity) and other process variables make reproducibility a serious challenge [27]. The low deposition rates, which are typically on the order of $1 \mathrm{~mL} / \mathrm{h}$ for lab spinning, result in low fiber production yield [28,29]. These factors all significantly challenge the commercial applicability of this method and its potential for the industrial scale-up of chitosan fiber production. Regardless of these drawbacks, various designs of the electrospinning method have been developed for mass production of nanofibers with satisfactory morphological accuracy. These designs are based on either multi-needle electrospinning or centrifuge electrospinning to increase fiber homogeneity, yield, and reproducibility, while needle-less electrospinning is used in an effoew5rt to reach industrial production yields [30-32].

A more recent and disruptive technique for nanofiber fabrication is solution blow spinning (SBS) [33]. A schematic drawing is shown in Figure 1C. This method offers high throughput and fiber diameter ranges similar to those of electrospinning without the need for high voltage and can be advantageous for ensuring high production yields. The SBS technique has been applied in both wet spinning (e.g., collection in coagulation baths) and dry spinning modes. In both of these modes, typically a polymer solution passes through the inner nozzle of a spinneret and a high-pressure gas (e.g., air, nitrogen, or argon) is emitted from the outer nozzle(s). Solvent from the solution jet is forced to evaporate, and the polymer chains are stretched and the tip-to-collector distance is projected, resulting in a solid fiber reaching the collector. A liquid collector bath is used for wet spinning; it is also possible to apply an electric field, and this technique is termed electro-blow spinning [34].

\subsection{Modified Chitosan Micro/Nanofibers and Their Applications}

It is challenging to fabricate chitosan as a submicron-sized fibrous form because chitosan has rigid D-glucosamine repeat units and the propensity to form inter- or intramolecular hydrogen bonds, leading to poor solubility in pure water as well as other common organic solvents. It has been shown that lowering the $\mathrm{pH}$ increases the water solubility of chitosan due to the protonation of primary amines [6]. The electrostatic repulsive forces between positive ammonium groups prevent intrachain hydrogen bonding, while the formation of interchain hydrogen bonds with water molecules enhances chitosan solubility in aqueous acidic solutions. Acetic acid has remained the most commonly used to adjust $\mathrm{pH}$. A high concentration of acetic acid in water has been used successfully as a solvent for the electrospinning of pure chitosan $[35,36]$. However, while lowering $\mathrm{pH}$ with acids decreases surface tension, it also has a contradictory influence on chitosan spinnability because it increases the viscosity of chitosan solutions [35]. Chemical modification has been used as another approach to increase the solubility and spinnability of chitosan. Examples of chemically modified chitosan derivatives are hexanoyl chitosan [37], PEGylated chitosan [38], carboxyethyl chitosan [39], and quaternized chitosan [39,40]. As a result, chitosan derivatives are not only soluble in acidic aqueous solutions but also in neutral and basic aqueous solutions [3,41]. For example, introducing carboxymethyl to the chitosan structure can greatly enhance the water solubility of chitosan [42]. However, the most facile method of improving the spinnability of chitosan involves blending chitosan with another polymer of either natural or synthetic origin. Co-spinning agents have been widely investigated by research groups worldwide and included collagen [43], gelatin [44], cellulose [45], poly(ethylene oxide) (PEO) [46,47], poly(vinyl alcohol) (PVA) [48,49], poly( $\varepsilon$-caprolactone) (PCL) [50,51], and poly(lactide-co-glycolide) (PLGA) [52,53]. This strategy has produced electrospun chitosan/polyurethane nanofiber membranes with diameters ranging from 200 to $400 \mathrm{~nm}$ that can effectively filter microparticles larger than $475 \mathrm{~nm}$ [54]. However, 
efficient production of electrospun nanofiber membranes that can capture nanoparticles (smaller than $100 \mathrm{~nm}$ ) remains difficult because the produced nanofibrous mats typically exhibit large variations in inter-fiber pore sizes and distributions. The membrane's filter functions can be enhanced by altering the fibers' electrostatic charges to promote chemi$\mathrm{cal} /$ physical interactions between them and between the fibers and the captured particles. It has been suggested that by utilizing the positive charge and excellent spinning properties of chitosan derivatives, a substrate for electrostatic viral repulsion (or capture) could be designed for personal protective clothing against the coronavirus SARS-CoV-2 as well as other viruses $[55,56]$.

The use of micro/nanofibers in the design and development of innovative products is a rapidly rising topic in the field of materials research. Aiming to highlight the future importance of natural polymers and their potential use in smart materials, this review focuses on the recent development of micro/nanofibers based on chitosan as well as its derivatives, blends, and composites. Challenges, trends, and opportunities in the use of chitosan-based nanofibers for food, textile, cosmeceutical, and biomedical applications are discussed herein.

\section{Chitosan-Based Nanofibers in Food Storage}

The use of chitosan for food packaging in the form of films and edible coatings has been well documented [57-59]. Chitosan films, while sustainable and environmentally friendly, typically have poor mechanical and barrier properties. Moreover, edible coatings and packaging that require direct contact with food may influence its taste. This problem is particularly salient for materials based on fibers composed of chitosan derivatives due to the solvents and chemicals that are presently used in fiber spinning $[57,58]$.

Nanofiber technology can potentially fabricate ultra-thin non-woven mats for food packaging applications [60]. Nanofibers with high chitosan content are used for antibacterial packaging, preserving the quality and safety of food products throughout distribution and storage due to their physical and chemical properties [61-64]. The antioxidant effect of chitosan is useful as a functional ingredient to improve the shelf lives of delicate food products [65]. From an environmental standpoint, packaging materials composed of chitosan nanofibers are bio-friendly, made from sustainable sources, and inherently biodegradable. Common methods of acquiring chitosan-based nanofibers for the food industry include functional components, also known as bioactives; these methods produce bio-functionalized nanofibers with specific properties.

Chitosan/PEO nanofibers (ChNFs) have been developed as the inner part of multilayer packaging that prolongs the quality of unprocessed red meat [66]. The preparation of this material involves spinning the nanofibers directly on top of the multilayer packaging material to form ChNFs-based packaging (ChNFP). ChNFs containing $90 \mathrm{wt} \%$ chitosan electrospun from $50 \%$ acetic acid solution have been reported to produce a smooth and homogenous nanofiber layer (Figure 2A) [66]. In a test of bacteria that are commonly responsible for food alteration and poisoning, the prepared ChNFs were found to stop the growth of E. coli, L. innocua, and S. aureus while slowing the propagation of S. Typhimurium in 2.5- $\mathrm{cm}^{2}$ nanofiber mats compared to a negative control sample (Figure 2B). Under representative storage conditions in a refrigerator, inoculated $E$. coli bacteria were reduced by $95 \%$ after seven days of storage in fresh meat wrapped in contact with ChNFP compared to meat wrapped with conventional packaging (Figure 2C); therefore, ChNFP reduced meat spoilage and maintained the appearance and smell of raw meat (Figure 2D).

The encapsulation of bioactive components into chitosan fibers is another way to utilize chitosan composite nanofibers in food packaging. Glucose oxidase (also termed herein notatin) is a promising bioactive that produces hydrogen peroxide and D-glucono-5-lakton in the presence of sugar and oxygen. Notatin has been integrated into chitosan/PVA/tea extract nanofibers to prevent food spoilage through antimicrobial activity and deoxidation [67]. The obtained membrane inhibited the growth of microbes under low oxygen conditions (up to $73 \%$ deoxidation). Recently, natural food preservatives have been applied 
to chitosan nanofibers. For example, pomegranate peel extract $(20 \mathrm{mg} / \mathrm{mL})$ has been encapsulated into a ChNFs mat for the fabrication of a food wrapping film to enhance the shelf life of bovine meat without losing its fresh smell [68]. Similarly, an antibacterial assay of ChNFs-loaded tea oil liposomes inhibited $99.99 \%$ of Salmonella sp. in chicken meat, effectively keeping the meat fresh after four days of storage [69]. In another study, the encapsulation of liquid smoke/thymol into chitosan nanofibers significantly delayed the microbiological spoilage of fresh fish fillets [70].

It is worth underlining that chitosan-based nanofibers are emerging as an effective platform for enzyme immobilization (like notatin in the example above) in food processing due to their surface properties, which enhance enzyme activity [65-67]. Furthermore, chitosan fibers can also be functionalized with enzymes for a controlled release of additives or catalytic products. Additionally, liquid smoke/thymol can be added to chitosan nanofibers to ensure long-term release properties [70]. A recent study showed that electrospun chitosan/xanthan gum nanofibers can be used as delivery carriers for curcumin to increase its physical stability in aqueous media [71]. The future use of chitosan nanofibers for integration into food packaging materials and food processing could potentially improve the efficacy, sustainability, and storage capacity of food production and holds promise for more environmentally friendly food distribution.
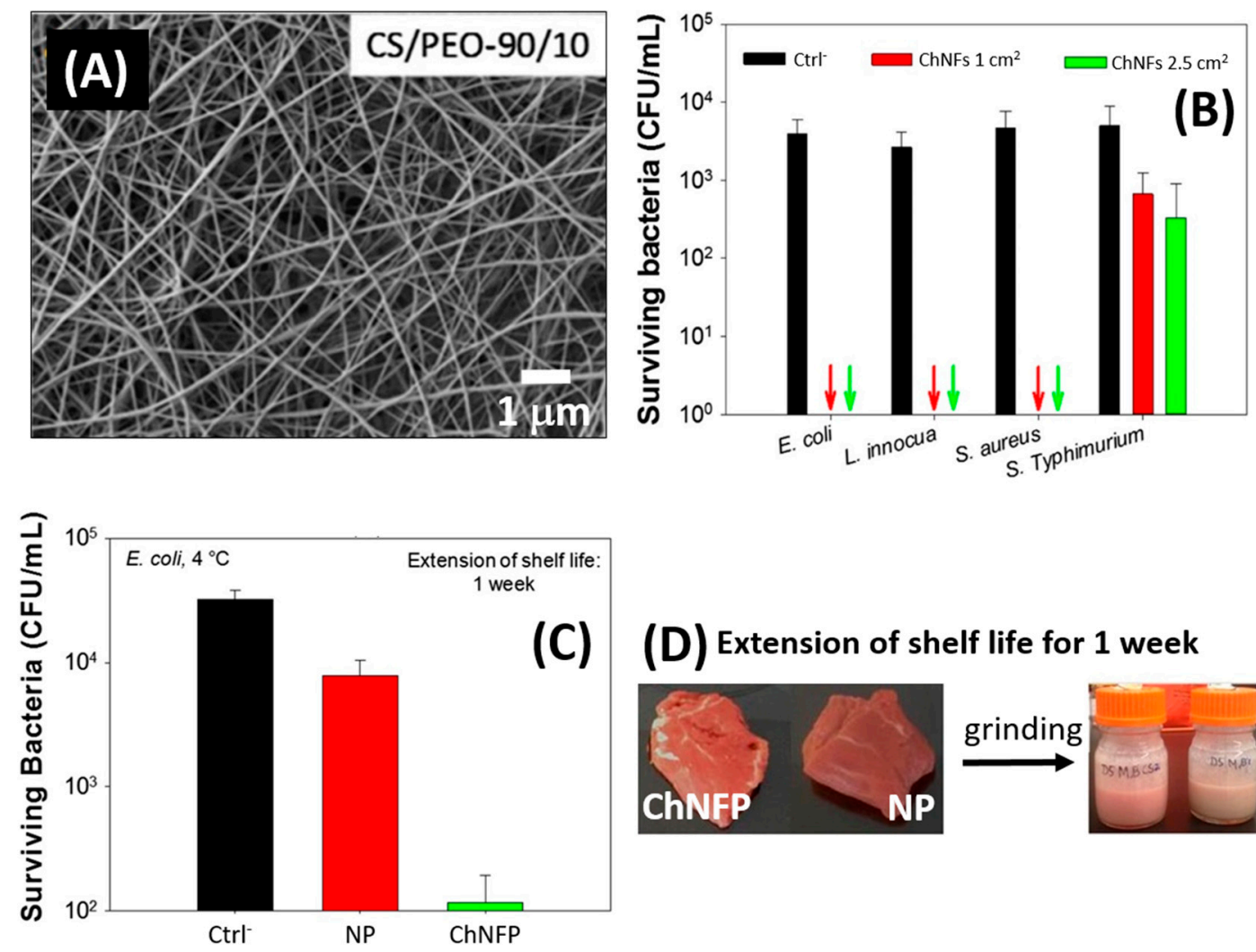

(D) Extension of shelf life for 1 week

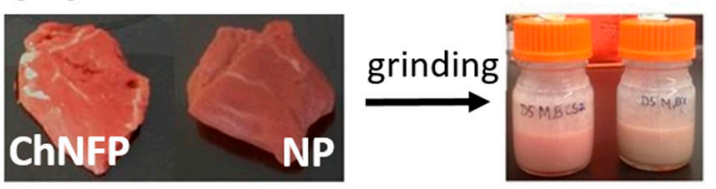

Figure 2. (A) An SEM picture of electrospun chitosan-PEO nanofibers (ChNFs) obtained from a 90/10 (w/w) solution in $50 \%$ acetic acid. (B) In vitro antibacterial activity of $1-\mathrm{cm}^{2}$ and $2.5-\mathrm{cm}^{2}$ swatches of ChNFs against E. coli, L. innocua, S. aureus, and S. Typhimurium compared to a negative control membrane $\left(\mathrm{Ctrl}^{-}\right)$. The arrows indicate total inhibition of E. coli, L. innocua, and S. aureus growth. The wider the area of ChNFs (i.e., larger chitosan content), the better the effect against $S$. Typhimurium. (C) In situ antibacterial activity of ChNFs-based packaging (ChNFP) against E. coli compared to negative control $\left(\mathrm{Ctrl}^{-}\right)$of inoculated meat and positive control of inoculated meat wrapped in neat conventional packaging (NP) after seven days of raw meat storage at $4{ }^{\circ} \mathrm{C}$. (D) Appearance of red meat wrapped in ChNFP and NP one week before and after grinding. Reprinted with permission from [66], copyright 2018 Wiley. 


\section{Chitosan-Based Microfibers Applied in the Textile Industry}

Chitosan is used extensively in textile dyeing and finishing due to its polycationic nature, which allows it to be combined with anionic dyes or to form strong ionic bonds with fabric materials $[69,70]$. However, there is far less literature on chitosan nanofibers than on synthetic polymer fibers in the textile industry. One often mentioned application of the nanofibrous structure of chitosan is the development of wound dressing materials. These dressings can carry and deliver pharmaceutical compounds when in contact with wounds and ulcers. Wound dressings are highlighted as one of the most attractive applications of electrospun chitosan nanofibers for medical textiles [72]. Similarly, metallic nanoparticles can be incorporated into chitosan fibers for use in other medical textiles. These textiles are designed for diagnostic or therapeutic purposes, such as biosensors and drug carriers. Biomedical applications are discussed in detail separately in Section 5. For non-biomedical textiles, there is little available documentation on the use of chitosan nanofibers, even though their potential uses are many. Herein, we focus on the recent developments of chitosan-based microfibers for the fabrication of smart textiles (also termed herein biofunctional textiles) [73].

A straightforward method of preparing pure chitosan microfiber yarns is wet spinning, though these approaches normally result in fibers $>5 \mu \mathrm{m}$ in diameter. Some perspectives on wet-spun chitosan and chitosan-blends are given in this section. There is an opportunity to use some newer disruptive spinning approaches such as solution blow spinning, electrospinning, and electro-blow spinning with coagulation baths to render these submicron fibers in processing. The typical processing stages for traditional wet-spinning of chitosan fibers are illustrated in Figure 3A [74]. Chitosan microfibers can be wet spun from a viscous chitosan solution (up to $8.5 \mathrm{wt} \%$ ) in acetic acid [75]. The obtained microfibers have an average diameter of approximately $20 \mu \mathrm{m}$ (Figure 3B), resulting in remarkable tensile strength $(28.7 \mathrm{~N}$, Young's modulus; $12.2 \mathrm{GPa})$ and elongation at break $(3.8 \%)$. The knitted fabrics were also constructed with 76-600 multi-filaments with strong breaking tenacity (Figure 3C). Using a similar technique, the obtained chitosan-grafted polyethylene glycol monomethyl ether (chitosan- $g$-mPEG) fiber improved by more than $50 \%$ in tensile strength and $200 \%$ in tensile modulus in contrast with the pure chitosan fiber [76]. These improvements were due to the enhancement of molecular entanglement and hydrogen bonding interactions. Moreover, the chitosan- $g$-mPEG fiber could regulate temperature through solid-solid phase change behavior. Therefore, this fiber would be a good choice for the fabrication of thermo-responsive fibers for smart textiles. Chitosan fibers with higher strength (by up to four times) were obtained by applying a glycine chloride ionic liquid spinning solution instead of the acetic acid solution [77]. Furthermore, the addition of inorganic nanoparticles (e.g., silver or gold) into chitosan-spinning dope could create functionalized knitted fabrics for use in textiles, dressings, scaffolds, and surgery meshes [78].

The production costs of pure chitosan fibers and finished textile products are high because they require many modification steps compared to commonly used synthetic polymers. Therefore, researchers typically blend chitosan with other polymers to reduce production costs and obtain good mechanical properties while maintaining the positive properties of chitosan. Interestingly, the use of natural polymers as alternatives for synthetic polymers (e.g., cellulose/chitosan composite fibers spun from a mixture of polymers in an aqueous solution of $\mathrm{LiOH} / \mathrm{KOH} /$ urea) has produced microfibers with excellent mechanical properties in both dry and wet states [79]. This observation gives hope for the sustainable textile industry for less reliance on synthetic polymers. 

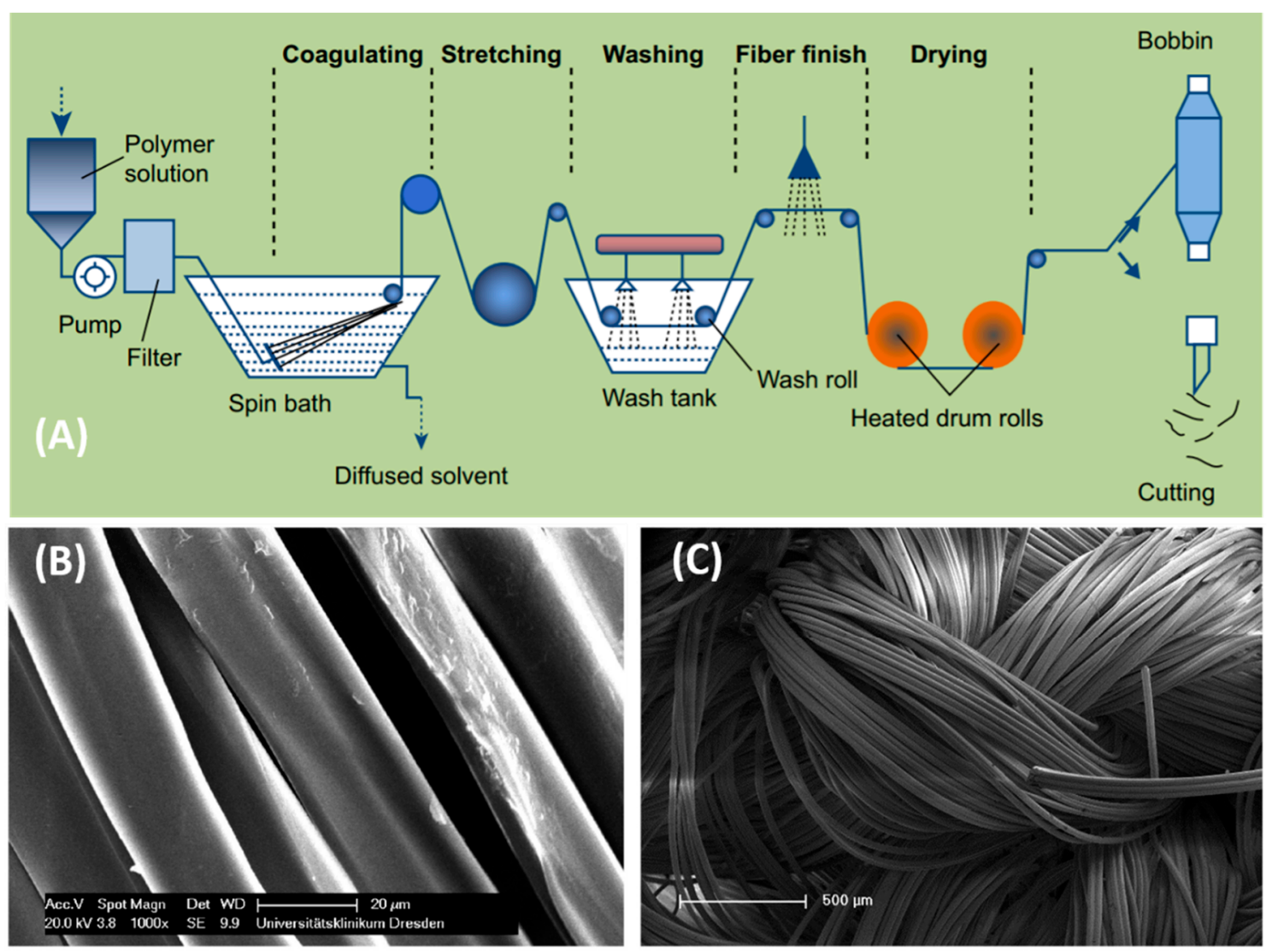

Figure 3. (A) Schematic illustration of the wet spinning process for yarn preparation adopted from [74]. (B) Chitosan microfibers wet spun from an $8.5 \mathrm{wt} \%$ solution. (C) The constructed knitted fabric. Reprinted with permission from [75], copyright 2014 Taylor \& Francis.

A commercial blending approach known as fiber blending or yarn blending is favored because it can be used to manufacture large-scale productions in traditional spinning mills. Chitosan-cotton-blended yarns were produced using this method, and the effects of different blending methods (fiber blending and sliver blending) on the tensile properties of the yarn were studied (Figure 4C) [80]. The chitosan fibers exhibited grooves on their longitudinal surfaces (Figure 4A) that could enhance friction between chitosan and chitosancotton fibers during blending, thus increasing the electrostatic charge and resulting in hairy structures (Figure 4B). With respect to mechanical properties, cotton fiber blending produced better tenacity and elongation properties than sliver blending (Figure 4D,E). Considering the chitosan fiber lengths produced by both blending methods, a decrease in tensile properties was observed along with an increase in fiber lengths. Given that the positive charges of chitosan molecules limit their textile applications due to their high electrostatic behavior, differences in yarn performance between chitosan/cotton-blended yarns and chitosan/polyacrylonitrile-(PAN)-blended yarns were studied by the same group [81]. The researchers selected two polymer fibers with opposite electric charge properties via friction-negative PAN fibers and positive cotton fibers-to blend with positive chitosan fibers. The tenacity of the chitosan/PAN-blended yarns was found to be superior to that of the chitosan/cotton-blended yarns. Given that the total charge approach was neutral when PAN was blended with chitosan, this mix was preferred for maximizing yarn performance and minimizing wastage.

All in all, advanced materials using mixes of natural polymers for smart and sustainable textiles have emerged as good candidates for the replacement of environmentally harmful synthetics and could significantly lower carbon dioxide emissions [82]. Aside from cellulose, chitin and chitosan are under consideration by the textile industry due to their sustainability and green credentials $[83,84]$. 

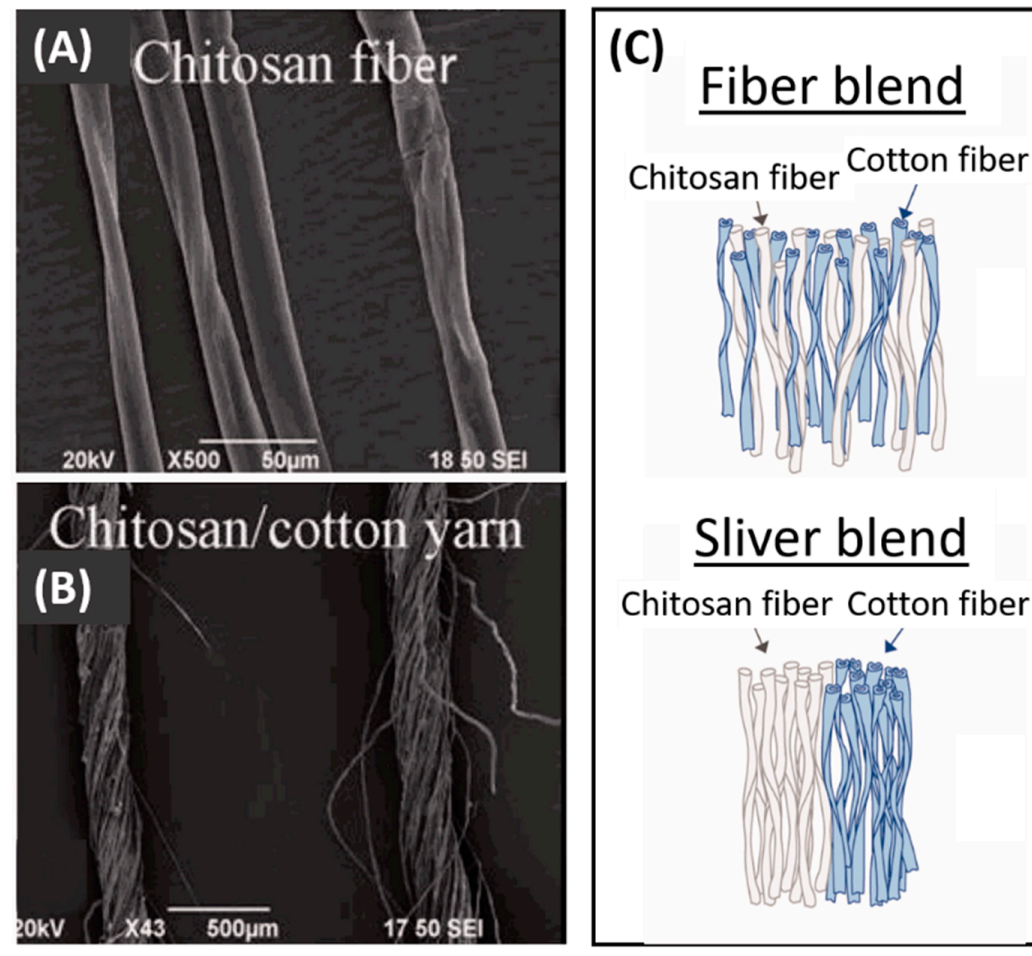

\section{Sliver blend}

Chitosan fiber Cotton fiber

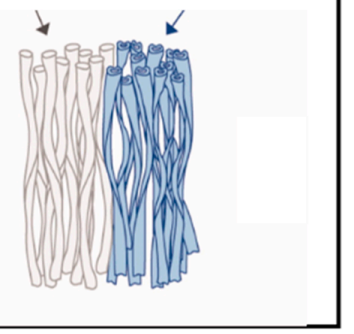

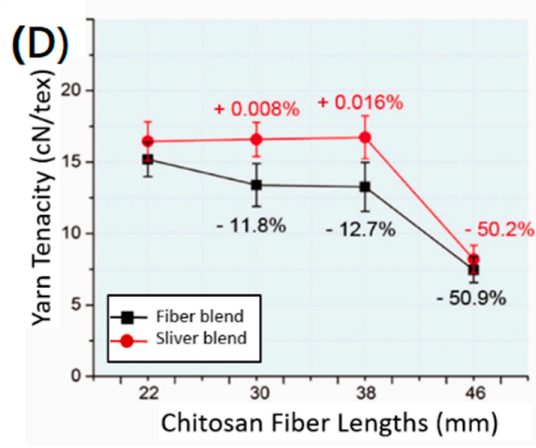

(E)

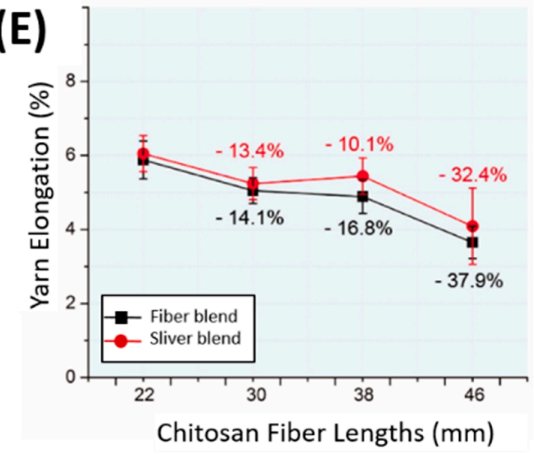

Figure 4. Micrograph images of surface structures in (A) chitosan fiber and (B) chitosan/cotton yarn. (C) Illustration of the blending methods. The yarn fiber blend showed higher (D) tenacity and (E) elongation than the yarn sliver blend at all chitosan fiber lengths. Reprinted with permission from [80,81], copyright 2014 \& 2017 SAGE Publications.

\section{Chitosan-Based Nanofibers Applied in Cosmeceuticals}

Due to the recent development of nanomaterials and biotechnology, chitosan and its derivatives are among the natural materials of interest for use in cosmeceuticals. These materials can act as either oral hygiene agents or nanocarriers for active compounds in cosmetic and personal care products $[85,86]$. The intrinsic antioxidant activity of chitosan is beneficial for skincare products due to its potential anti-aging effects [87]. In particular, the antioxidative carboxylation of chitosan inhibits the activity of matrix metalloproteinases (MMPs) that dissolves the collagen matrix of connective tissues and protects against reactive oxygen species (ROS) that harm tissues during radiation treatment, sunburns, and biological stress [88]. The strong antibacterial activity of chitosan against Streptococcus mutans, a major cause of dental decay, has made way for the addition of chitosan nano/microparticles to oral healthcare products, such as toothpastes and mouth rinses [89,90]. Finally, chitosan and its derivatives can also interact with keratin, forming elastic and resistant films on individual hair strands that protect against wear and damage, thus enhancing the appearance and conditioning of hair [91].

Although chitosan derivatives have been applied as innovative materials for the manufacture of various cosmeceutical products, only a limited number of cosmeceutical products utilize chitosan nanofibers. To the authors' knowledge, the only cosmeceutical product reported to utilize these nanofibers is a chitin nanofibril mask designed for use as a facial dressing for medical purposes; the nano/micropores in this product allow bioactive substances through the dressing and block microbes and contaminants from reaching the healing skin [92]. This mask has been described as a transparent, flexible, and thin film made by casting technology. Nanofibrous chitosan and its derivatives can be used to cast custom-made dressing scaffolds with antioxidant and antimicrobial properties. Skin-friendly dressing filters based on these nanofiber membranes typically contain preservatives, drugs, and/or active healing agents and can be prepared by either electrospinning or blow spinning, producing a functionalized nanofiber layer for wound healing, skin therapy, and other cosmeceutical applications (Figure 5). 


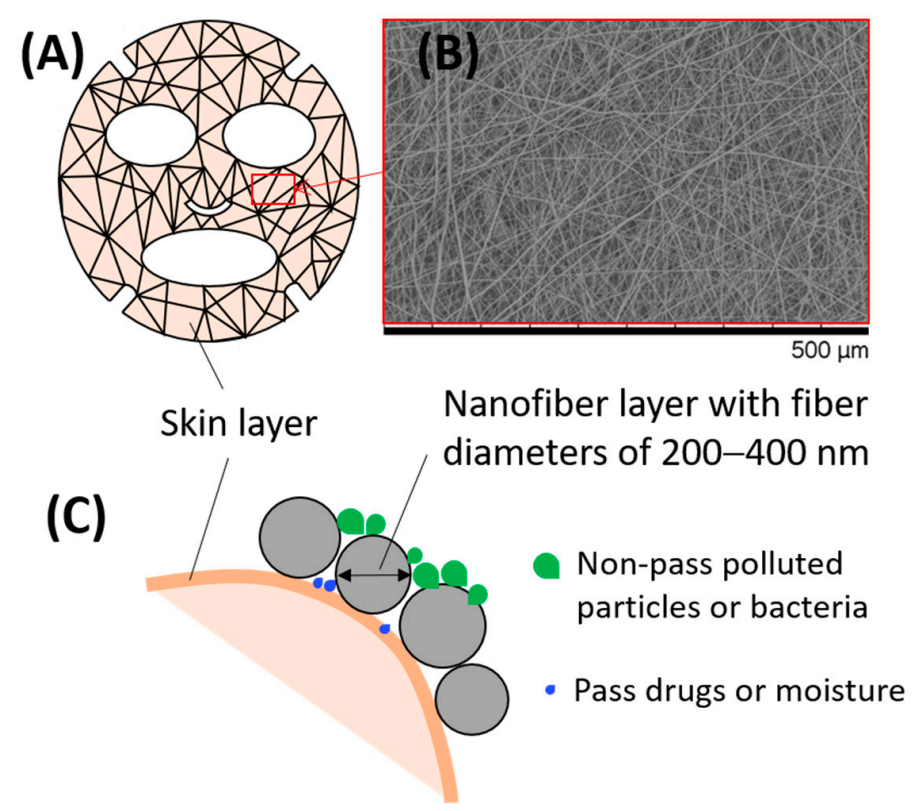

Figure 5. (A) A protective cosmeceutical mask for facial skincare after burns based on (B) a chitosan nanofiber membrane. (C) Schematic illustration of the nanofiber layer on the skin surface. Depending on the materials and active ingredients used in formulation for manufacturing, the nanofiber face mask can exhibit various functionalities, including increased contact area with the skin, protection of the skin from microsized polluted particles and bacteria, and maintenance of skin conditioning and moisture.

\section{Chitosan-Based Nanofibers in Biomedical Applications}

To date, the most important achievements in the application of chitosan-based nanofibers have been in the biomedical field. This is due to the unique hemostatic properties of these nanofibers, which promote platelet aggregation and neutrophil/macrophage activities [93]. For example, chitosan nanofibrous scaffolds can offer an excellent biocompatible environment for cell seeding and the promotion of tissue growth. One of the major challenges of tissue engineering is that of finding appropriate biodegradable materials that are non-toxic and compatible (physiologically and biochemically) with the human body. As mentioned previously, chitosan can be blended with natural and/or synthetic polymers to improve the spinnability, stability, mechanical properties, and biofunctionality of nanofibers and scaffolds. An abundance of bioactives, drugs, and therapeutic compounds have been incorporated into chitosan nanofibrous meshes to meet specific requirements as wound healing agents, antimicrobial agents, growth factors, and drug carrier agents [94]. This section reviews specific examples of chitosan nanofiber-based materials for wound healing, targeted delivery of bioactive compounds, and tissue engineering.

\subsection{Wound Healing}

Wound healing is a dynamic process consisting of four phases: hemostasis, inflammation, growth, and remodeling through a timed sequence [95]. Protective patches (i.e., wound dressings) have probably been used to treat wounds while they heal for as long as humans have lived, but wound dressings still have a long way to go before they can improve and/or speed up the natural healing process. There is still a grave need for multifunctional wound dressings that can aid in the healing of advanced chronic ulcers in immunocompromised patients [96]. Various designs of wound dressings in the form of films, hydrogels, sponges, and foams made of natural or synthetic materials (or combinations of these materials) are currently in use [97]. Wound dressings made from chitosan-based nanofibers have emerged as a new class of wound dressings that show superior properties in terms of biocompatibility, biodegradability, porosity, and antimicrobial activity. These dressings can also provide an optimum moisture environment, absorb wound exudate, 
and (in some cases) accelerate wound recovery [98]. Aside from chitosan, the pros and cons of a variety of biopolymers used in wound treatments have been extensively covered by literature reviews $[96,99,100]$. The schematic illustration in Figure 6 A,B shows the application of a polymeric wound dressing with antibacterial activity to cover an open wound [101]. Such a functional nanofiber-based dressing not only protects the wound but can also modulate the release of therapeutic agents embedded in the fibrous network to aid in healing (Figure 6C) [102].

In one study, researchers reported that composite nanofibers made from honey, tripolyphosphate, and chitosan loaded with capsaicin and gold nanoparticles can enhance the wound closure rate through antibacterial effects and increased dermal cell proliferation in the nanofibrous scaffold [103]. In another study, blended chitosan nanofibers (also called hybrid fibers) prepared by electrospinning were used to manufacture a bicomponent nanofibrous mat containing chitosan and poly(lactide) (PLA) [104]. This mat effectively inhibited the growth of $S$. aureus and E. coli bacteria in wounds compared to a corresponding solvent-cast chitosan-PLA film. It has also been shown that core-sheath-structured PLA-chitosan nanofibers can promote fibroblast adhesion and proliferation [105]. Aside from PLA, PEO and PCL are also frequently used to fabricate hybrid fibers together with chitosan due to their interaction with tissue and favorable mechanical properties $[50,106]$. Natural ingredients, such as aloe vera, have also been used in chitosan-PCL nanofibers to improve the hydrophilicity and antibacterial properties of the hybrid material [107]. More structurally advanced, electrospun multilayer scaffolds have also been fabricated for wound healing [108]. A first layer providing mechanical support is composed of PCL or a PCL/cellulose acetate blend, while a second layer designed to come in direct contact with the wound surface is composed of ChNFs. These scaffolds exhibited a porosity of $85 \%$ with high water vapor permeation, making them suitable for treating an exudative wound. These scaffolds also allow for swelling up to 370\% without any loss of mechanical or structural properties and are biocompatible with fibroblast cells, making them potentially useful as resorbable dressings for full-thickness wounds.

\subsection{Delivery of Bioactive Compounds}

Bioactive molecules and therapeutic compounds have been combined with chitosan nanofiber membranes to further improve their performance in wound dressings. One approach to improving the performance of chitosan-based wound dressings involves incorporating inorganic nanoparticles into the chitosan-containing nanofibers to promote wound healing and/or improve their antibacterial potential. Nitric oxide (NO), which plays a vital role in the wound healing processes from inflammation to tissue remodeling, has been adsorbed into electrospun mats of PCL/chitosan nanofibers by drop coating [109]. The NO released from these materials helps to accelerate the closure of acute, experimental wounds (Figure 6D-F). Other inorganic compounds that have wound healing properties and have been incorporated into chitosan nanofibers include $\mathrm{ZnO}$ [110], $\mathrm{Fe}_{3} \mathrm{O}_{4}$ [44], $\mathrm{TiO}_{2}$ [111], and various metals (gold, silver, and copper) [112]. It should be noted that, depending on the context and application, silver and copper are not only antimicrobial but can be toxic and thus should be applied with caution $[113,114]$. It is also worth mentioning that the incorporation of metals into nanofiber scaffolds can provide electrical conductivity to the fibers and help generate electric or magnetic fields with various applications, such as wearable smart textiles, biosensors, or the direction of cell migration. For example, loading magnetic nanoparticles $\left(\mathrm{Fe}_{3} \mathrm{O}_{4}\right)$ into chitosan nanofibers allows the materials to be heated, making them effective for hyperthermia treatment [115].

Another composite natural nanofiber system has been reported to contain fibers of $40 \mathrm{wt} \% \mathrm{~N}$-carboxyethyl chitosan (a water-soluble chitosan derivative) and $60 \mathrm{wt} \%$ PVA, with incorporated silk fibroin nanoparticles. These fibers were fabricated by electrospinning [116]. The presence of silk fibroin nanoparticles lent more strength to the material and facilitated increased fibroblast cell adhesion and growth but caused the material to degrade faster in biological systems. 


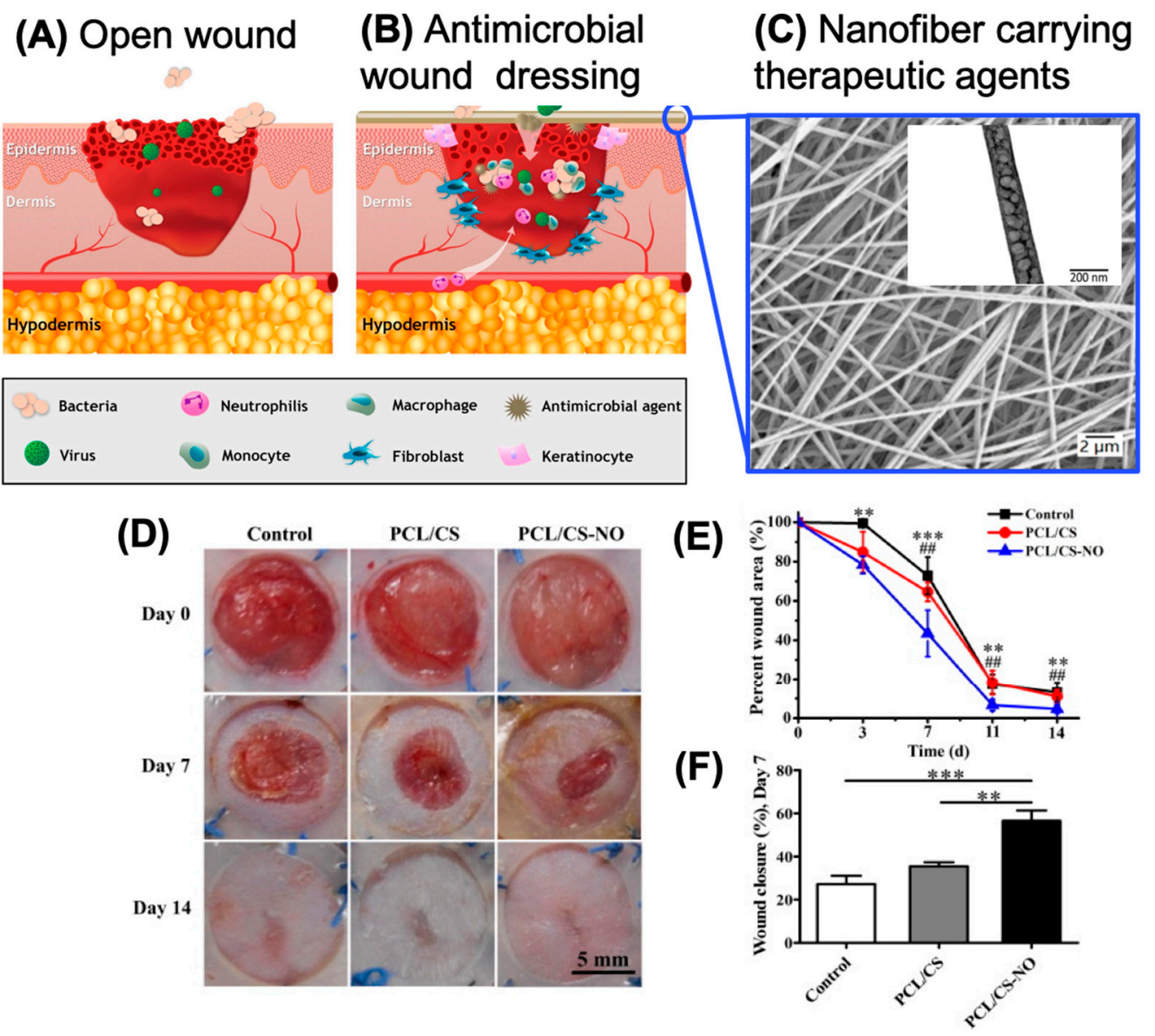

Figure 6. The wound healing process of (A) an open wound covered with (B) an antimicrobial wound dressing. When the antimicrobial dressing covers the wound bed, it acts as a barrier to prevent bacteria and viruses from invading the wound. Dressings with embedded functional agents can promote the healing rate and stimulate the immune system to speed up skin regeneration in immunocompromised patients. Reprinted with permissions from [101], copyright 2018 Elsevier. An example in (C) shows chitosan-based nanofibers with $0.3 \% w / v$ of polyhexanide (a commonly used wound disinfectant) embedded, used to fabricate an antimicrobial surface on a surgical dressing. Reprinted with permissions from [102], copyright 2020 Springer. (D) In vivo wound healing in a mouse model using a PCL-chitosan nanofibrous dressing with or without incorporated nitric oxide. The nitric oxide-containing material promotes faster wound closure, as illustrated in (E) by the percentage of open wound area and in $(\mathbf{F})$ by the percentage of wound closure. Reprinted with permissions from [109], copyright 2018 Elsevier. ${ }^{* *} p<0.01,{ }^{* * *} p<0.001, \# \# p<0.05$.

Chitosan-based nanofibrous materials for use in wound care can be further improved by adding multiple biochemical stimuli, e.g., growth factors and antibacterial molecules. In one study, the researchers loaded two synergetic growth factors into ChNFs [117]. When applied, these fibers release a burst of vascular endothelial growth factor (VEGF), a key mediator for angiogenesis and granulation tissue formation, which accelerates early-stage healing, followed by a sustained release of platelet-derived growth factor-BB (PDGF-BB), which promotes connective tissue growth and remodeling.

For the treatment of severe burns, $2 \%(w / v)$ bromelain (a debriding agent commonly used in burn treatment) was added to electrospun chitosan nanofibers [118]. When applied to burns, this material reduced the burn wound area and significantly increased the density of collagen tissue compared to ordinary passive burn dressings.

Similarly, Zataria multiflora (ZM) essential oil is a strong natural antimicrobial agent and has been incorporated into electrospun chitosan/PVA/gelatin nanofibers to fabricate wound dressings for use after surgery and on burn wounds [119]. These nanofibers were loaded with $10 \%(v / v) \mathrm{ZM}$ and completely stopped the growth of bacteria over $24 \mathrm{~h}$ of incubation. Although this material was highly effective against microbial growth, 
its strength was significantly reduced. Several other natural healing agents have also been tested as adjuvants to composite chitosan nanofibers with varying results, including a curcumin-loaded chitosan/poly(propylene carbonate) [120] and a henna-leaf-extractloaded chitosan-based scaffold [121], both of which showed positive effects on acute wound healing in experimental models.

Finally, the combination of different chitosan derivatives can also be used to fabricate advanced active wound dressings. In one experiment, electrospun chitosan/PVA nanofibers were manufactured with different concentrations of carboxymethyl-chitosanencapsulated antibacterial peptide nanoparticles (OH-CATH30, a clinical drug) [49]. This material showed dual antibacterial activity and promoted acute wound healing. The resulting nanofiber system was not only suitable for use as a wound dressing but was also recognized as a good drug-carrier platform for other biomedical applications.

\subsection{Tissue Engineering}

\subsubsection{Skin}

Wound dressings based on nanofibers can be effective in protecting wounds from contamination and infections and can be modified to promote skin repair and therefore shorten healing time. These devices may also be designed to deliver therapeutic drugs [122]. Most dressings are thin isotropic materials that can restrict the migration of cells through thickness. Acting as a barrier to growth and migration, this can cause skin cells to behave abnormally and cause aberrant skin healing with fibrosis and scarring [123]. This shortcoming is particularly salient for deep, full-thickness wounds involving both the epidermis and the dermis [124]. It has been suggested that using nanofibers to construct a 3D scaffold that mimics the structure of the skin's extracellular matrix could produce better conditions for cell growth and promote skin tissue repair and regeneration [125]. Such novel materials could also have a multi-layered design with zones that mimic the layers of the skin to provide a multidimensional roadmap for cells to complete the healing of full-thickness wounds.

Several authors have recently reported on experiments combining nanofibers with hydrogels in a 3D structure for tissue engineering and wound care [126-128]. One experiment investigated a bilayer scaffold consisting of hybrid nanofibers made of human hair keratin and chitosan for epidermal cell ingrowth and a gelatin-methacrylate hydrogel to support the connective tissue cells of the dermis [128]. The use of chitosan nanofibers together with keratin could potentially overcome the poor mechanical properties of chitosan while enhancing the structural stability of the keratin substrate. This artificial skin structure has shown some promise in the lab but lacks in vivo data; thus, it is difficult to evaluate this structure's potential for clinical use.

In co-culture tests with this two-layered structure, fibroblasts were added to the hydrogel part and keratinocyte cells were added to the nanofiber mesh on the opposite side (Figure 7A,B). Cell populations then migrated and proliferated, forming distinctively different layers: an epidermis-like layer on the nanofiber mesh and a dermis-like layer in the hydrogel (Figure 7C). In a similar but contrary approach, a two-layer skin construct consisting of an epidermal side made of collagen hydrogel reinforced by a fibrin-coated polylactide nanofibrous membrane on the epidermal side was manufactured and tested in co-cultures of dermal cells [129]. The dermal layer was a fibrin-coated poly(L-lactide) nanofibrous membrane that integrated fibroblasts, mimicking the dermis layer of the skin. A collagen-based hydrogel was then added on top of the fibrous membrane and seeded with keratinocytes, which spread out to form a homogeneous basal layer that mimicked the epidermis layer of the skin (Figure 7D). Chitosan nanofibers were not used in this material, but it is envisaged that the added value of chitosan could make this construct more bioactive, stronger, and more protective against microbial invasion when applied in the clinic.

In general, skin is an extremely hyperelastic material with the capacity to reorganize its structure, to repeatedly stretch far beyond its normal dimensions and return to 
its original state when strain is released, without any loss of mechanical integrity. An optimal skin-mimicking material must therefore be sufficiently tough and elastic to last long enough for the skin to heal. Significantly, the skin-mimicking strategies described in the present literature are lacking in mechanical properties such as tension, torsion, and viscoelasticity. In addition, key information on the clinical performance of these strategies is lacking, especially with respect to vascularization, cell differentiation, tissue integration, degradability, and infection control. This may hinder our understanding of the mechanism of vascularization for tissue-engineered skin products. More work is needed to consolidate the proof of concept for complex, biomimicking skin substitutes. However, it seems reasonable that the versatility, availability, and favorable biological, environmental, and mechanical properties of chitosan nanofibers make them natural constituents of future skin tissue engineering materials.
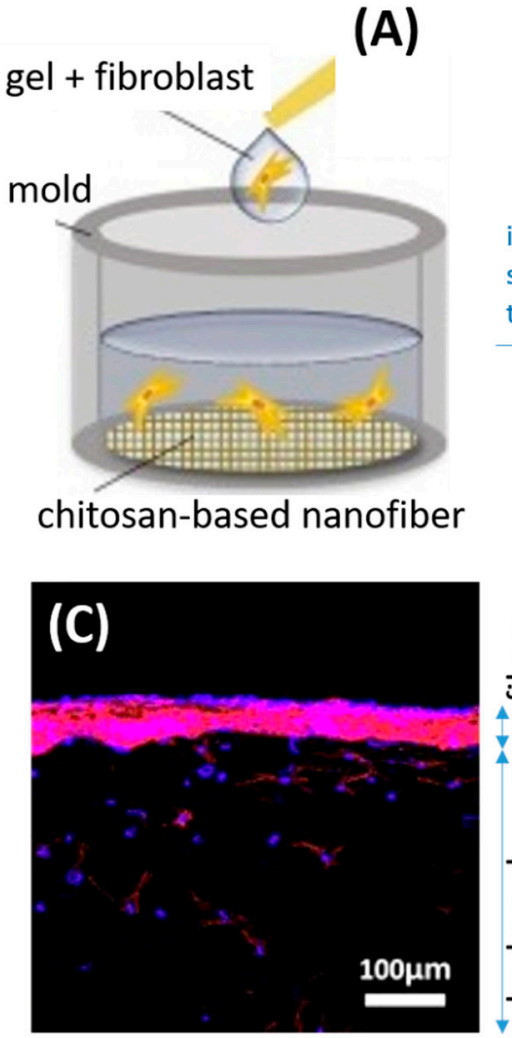

(B)

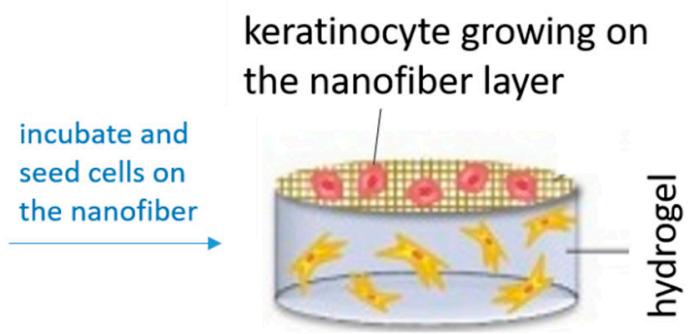

\section{bilayer hybrid scaffold seeded with fibroblasts and keratinocytes}

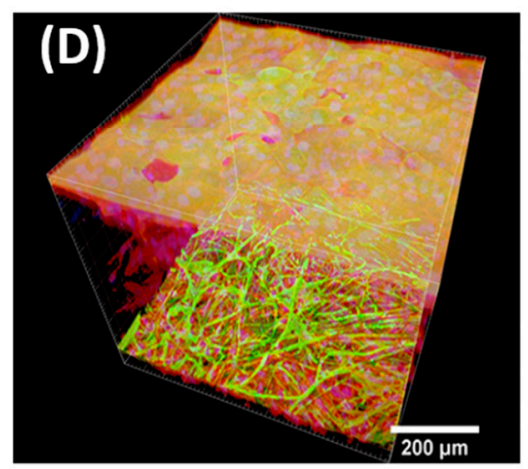

Figure 7. A bilayer scaffold composed of a nanofiber mat and a hydrogel mimics the layered nature of skin. The chitosanbased nanofiber was prepared by electrospinning, while the hydrogel was synthesized by photopolymerization. (A) Human fibroblasts were encapsulated in the gel and poured into a mold with the nanofiber mat placed on the bottom. (B) After a short incubation period, the hydrogel was flipped over with the nanofiber mat side up, and keratinocyte cells were seeded onto the nanofiber surface. After co-culturing, encapsulated fibroblasts (blue) proliferated in the hydrogel matrix, while keratinocyte cells (red) formed a layer on top of the fibrous scaffold, mimicking the epidermis and the dermis. (C) A cross-section of the cellularized bilayered material. Reprinted with permissions from [128], copyright 2017 Elsevier. (D) A 3D scaffold made from a nanofiber-hydrogel composite and captured by confocal microscopy. The fibrin-coated nanofiber mat (green) enabled the fibroblasts (red) to migrate from the nanofibers and into the collagen hydrogel (middle layer), mimicking the skin's dermis. Different from the 3D scaffold in (B), the hydrogel in (D) constitutes the top layer supporting the embedded keratinocytes (yellowish), mimicking the skin's epidermis. Reprinted with permissions from [129], copyright 2019 Dove Medical Press.

\subsubsection{Bone}

Chitosan is structurally similar to glycosaminoglycan, which is found in bone; thus, chitosan is considered to be one of the most promising natural biopolymers for bone tissue engineering [130,131]. A bone biomimetic scaffold based on nanocomposite nanofibers of 
chitosan and hydroxy-apatite (HAp; 70/30 w/w) was synthesized by electrospinning [132]. The obtained nanofibers had an average diameter of approximately $214 \mathrm{~nm}$ and contained proper, structurally preserved, HAp nanocrystallites. When tested in an experimental model for bone growth, the nanofiber scaffold showed promising osteoconductive properties. In a further development, collagen $(7.2 \mathrm{wt} \%)$ was added to the electrospun chitosan/HAp fibers in an effort to enhance osteoblast-scaffold interaction and promote bone formation. Experiments demonstrated that this chitosan/HAp/collagen biocomposite scaffold significantly improved bone formation compared to HAp alone [133]. In another recent study, a scaffold of electrospun ChNFs reinforced with halloysite nanotubes (aluminosilicate clay mineral, HAL) was designed and fabricated for bone regeneration [134-137]. These nanofibers incorporated approximately $5 \mathrm{wt} \% \mathrm{HAL}$ and had a diameter of approximately $120 \mathrm{~nm}$. The resulting scaffold material exhibited a porous structure with high tensile strength. When tested in experimental models, the material showed promising osteoinductive properties that make it a good candidate for testing as a bone graft substitute material.

\section{Future Prospects}

Recently, significant progress has been made in the fabrication of multicomponent, multifunctional chitosan-based nanofiber systems [54,102]. Functionalizing these fibers with various bioactives, drugs, therapeutic agents, and conductive or magnetic components is now a common strategy to further boost and tune the properties of chitosan and its derivatives $[49,94,138]$. However, while these technologies are currently available, challenges remain since adding materials could be sensitive to the processing environment (heat, humidity, or $\mathrm{pH}$ ), potentially losing functionalities in applications. Therefore, chitosan-based fibers still require further development and testing for improved function both as medical devices and commercial products in daily life.

The connection between the biological properties and physical characteristics of these fibrous materials remains to be investigated and fully understood on all scales. For example, advanced nanofiber configurations (e.g., core-sheath nanofibers, aligned nanofibers, and gradient nanofibers) show different biological and mechanical properties [139]. This implies that controlling the physical shapes and chemical configurations of these fibers is instrumental to the design of smart materials with superior nanoscale properties, such as controlled-release functions, the guiding of cell adhesion and migration, conductivity and magnetism for biosensor applications, improved strength and elasticity, and potentially nanoscale self-assembly and self-disassembly (e.g., for injectable biomedical remedies and perpetual sustainable recirculation) [140-142]. Further post-spinning treatments could also improve adhesion between fibers for improved fabrics in food packaging or smart clothing or for improved bioactivity in biomedical applications. Each surface modification strategy has its potential in the development of multifunctional fibrous scaffolds. By combining process parameters of pre- and post-spinning treatments, researchers can create advanced scaffolds with tuning properties while preserving nanofiber integrity.

Moreover, the completely degradable nature of chitosan-based materials requires further attention. Given that the degradation profile is directly related to the precise chemical structure of the polymer and the hierarchical architecture of the fibers, the degradation of chitosan-based fibrous materials can be tailored [143,144]. This property alone, especially if it can be controlled and triggered, holds great promise for sustainable food, cosmeceutical, and biomedical applications.

A major future application of chitosan-based nanofibers is in tissue engineering. Materials scientists are designing more and more advanced materials for wound care and tissue graft substitutes. Although fiber spinning is evidently a versatile technique for sub-micron fiber production, it still has limitations, for example the reproducibility due to a large number of controlled parameters and subsequently affecting dimensions and morphology of final product requirements [145-147]. Due to increased regulatory restrictions particularly in Europe (European Tissue and Cells Directive [148]) and the new medical device regulation (MDR) [149], on fibers from animal sources, we are likely to see a shift in use of 
collagen fiber for medical use towards more sustainable biomaterials such as chitosan [150]. The combination of advanced fabrication methods (e.g., sub-micron fiber spinning and 3D printing methods) would help to produce multidimensional chitosan-based materials with structures that mimic some aspects of natural tissues. These materials have shown outstanding biological qualities while also exhibiting viscoelastic properties, high compressive strength, and potential for controlled release and resorption [151]. Together, these properties make chitosan-based materials ideal as a basis for developing the next generation of smart materials for tissue engineering purposes.

A selection of commercial chitosan-based materials based on non-woven fibers that are available for advanced wound care market is summarized in Table 1. Although chitosanbased micro/nanofibers have successfully been scaled-up and entered several clinical trials, issues regarding mass production of sub-micron chitosan fibers are still unsolved. To ensure commercial success for sub-micron chitosan fibers in the medical market, challenges such as homogeneity of raw materials, reproducibility, regulatory obstacles, and production cost must be addressed.

Table 1. Commercial chitosan-based fiber products on the medical wound care market.

\begin{tabular}{|c|c|c|c|c|}
\hline Material & Product Name & Specification & Approved Market & Manufacturer \\
\hline Chitosan & Celox $^{\mathrm{TM}}$ Rapid & $\begin{array}{c}\text { Hemostatic dressings contain activated } \\
\text { chitosan bonded to a high-density } \\
\text { gauze }\end{array}$ & USA, EU & $\begin{array}{c}\text { Medtrade Products Ltd., Crewe, } \\
\text { UK }\end{array}$ \\
\hline Chitosan & axiotstat $^{\circledR}$ & $\begin{array}{l}\text { Hemostatic dressings have } \\
\text { mucoadhesion due to charge }\end{array}$ & USA, EU & $\begin{array}{l}\text { Axio Biosolutions Pvt. Ltd., } \\
\text { Ahmedabad, India }\end{array}$ \\
\hline Chitosan & ChitoFlex ${ }^{\circledR}$ PRO & $\begin{array}{c}\text { Hemostatic dressings for the treatment } \\
\text { of moderate to severely bleeding } \\
\text { wounds }\end{array}$ & USA, EU & $\begin{array}{c}\text { Tricol Biomedical, Inc., Portland, } \\
\text { Oregon, USA }\end{array}$ \\
\hline Chitosan & ChitoSAM $^{\mathrm{TM}} 100$ & $\begin{array}{l}\text { Hemostatic dressings optimized to } \\
\text { stop the bleed fast }\end{array}$ & USA, EU & $\begin{array}{l}\text { SAM }^{\circledR} \text { Medical, Tualatin, } \\
\text { Oregon, USA }\end{array}$ \\
\hline Chitosan & ChitoClot Gauze & $\begin{array}{c}\text { Hemostatic dressings reduce bleeding } \\
\text { time }\end{array}$ & USA, EU, Taiwan & $\begin{array}{l}\text { BenQ Materials Corporation, } \\
\text { Taoyuan, Taiwan }\end{array}$ \\
\hline Chitosan & Chitoskin ${ }^{\circledR}$ & $\begin{array}{l}\text { A non-woven chitosan-based skin } \\
\text { substitute }\end{array}$ & China & $\begin{array}{l}\text { Hainan Xinlong Nonwovens Co., } \\
\text { Ltd., Haikou, China }\end{array}$ \\
\hline Chitosan & Chito-Seal & $\begin{array}{l}\text { Hemostatic dressings for bleeding } \\
\text { wounds }\end{array}$ & USA & $\begin{array}{c}\text { Abbott Vascular, Inc., Chicago, } \\
\text { Illinois, USA }\end{array}$ \\
\hline Chitosan & Clo-Sur P.A.D ${ }^{\circledR}$ & $\begin{array}{c}\text { A non-woven topical pad accelerates } \\
\text { hemostasis }\end{array}$ & USA & $\begin{array}{l}\text { Scion BioMedical, Miami, } \\
\text { Florida, USA }\end{array}$ \\
\hline Chitosan & ExcelArrest ${ }^{\circledR}$ XT & $\begin{array}{c}\text { Hemostatic dressings made of } \\
\text { modified chitosan that accelerates the } \\
\text { clotting process }\end{array}$ & USA, EU & $\begin{array}{l}\text { Hemostasis, LLC, Saint Paul, } \\
\text { Minnesota, USA }\end{array}$ \\
\hline Chitosan/alginate & Tromboguard $^{\circledR}$ & $\begin{array}{c}\text { Act as the contact layer of a multilayer } \\
\text { hemostatic dressing }\end{array}$ & EU & TRICOMED S.A., Łódź, Poland \\
\hline Chitosan/rayon & ChiPro face mask & $\begin{array}{l}\text { Chitosan face masks contain } 45 \% \\
\text { chitosan and } 55 \% \text { rayon }\end{array}$ & Germany & $\begin{array}{c}\text { ChiPro GmbH, Bremen, } \\
\text { Germany }\end{array}$ \\
\hline Chitosan/polynosic & Chitopoly $^{\circledR}$ & $\begin{array}{l}\text { Antimicrobial wears made of chitosan } \\
\text { and polynosic fiber }\end{array}$ & Japan & $\begin{array}{l}\text { Fuji Spinning Co., Ltd., Tokyo, } \\
\text { Japan }\end{array}$ \\
\hline Chitosan/viscose & Crabyon $^{\circledR}$ & $\begin{array}{c}\text { The Crabyon }{ }^{\circledR} \text { fiber that made of } \\
\text { chitosan and viscose used for the } \\
\text { textile market }\end{array}$ & Switzerland & $\begin{array}{l}\text { Swicofil AG, Lucerne, } \\
\text { Switzerland }\end{array}$ \\
\hline Chitosan & Chitopack $C^{\circledR}$ & $\begin{array}{l}\text { Cotton-like chitosan prepared by wet } \\
\text { spinning }\end{array}$ & Japan & Eisai Co., Ltd., Tokyo, Japan \\
\hline
\end{tabular}

\section{Conclusions}

Chitosan-based micro/nanofibers have demonstrated a desirable platform for a broad spectrum of applications. An overview of recent developments in chitosan-based micro/nanofibers has been summarized in this review (shown in Table 2). The desired intrinsic properties of chitosan conformed into high-surface-area nanofiber constructs can now be used as edible coatings to preserve the food quality, non-woven fabrics with sustainability and green credentials, antibacterial face masks in cosmetics, or biomedical substrate for skin and bone tissue regeneration. Owing to the latest advances in materials science in synergy with biotechnology, chitosan is seen as valuable natural raw material for novel products that facilitate healthy and sustainable living. 
Table 2. Summary of chitosan-based micro/nanofibers for sustainable food packaging, smart textiles, cosmetics, biomedical applications, and their characteristics.

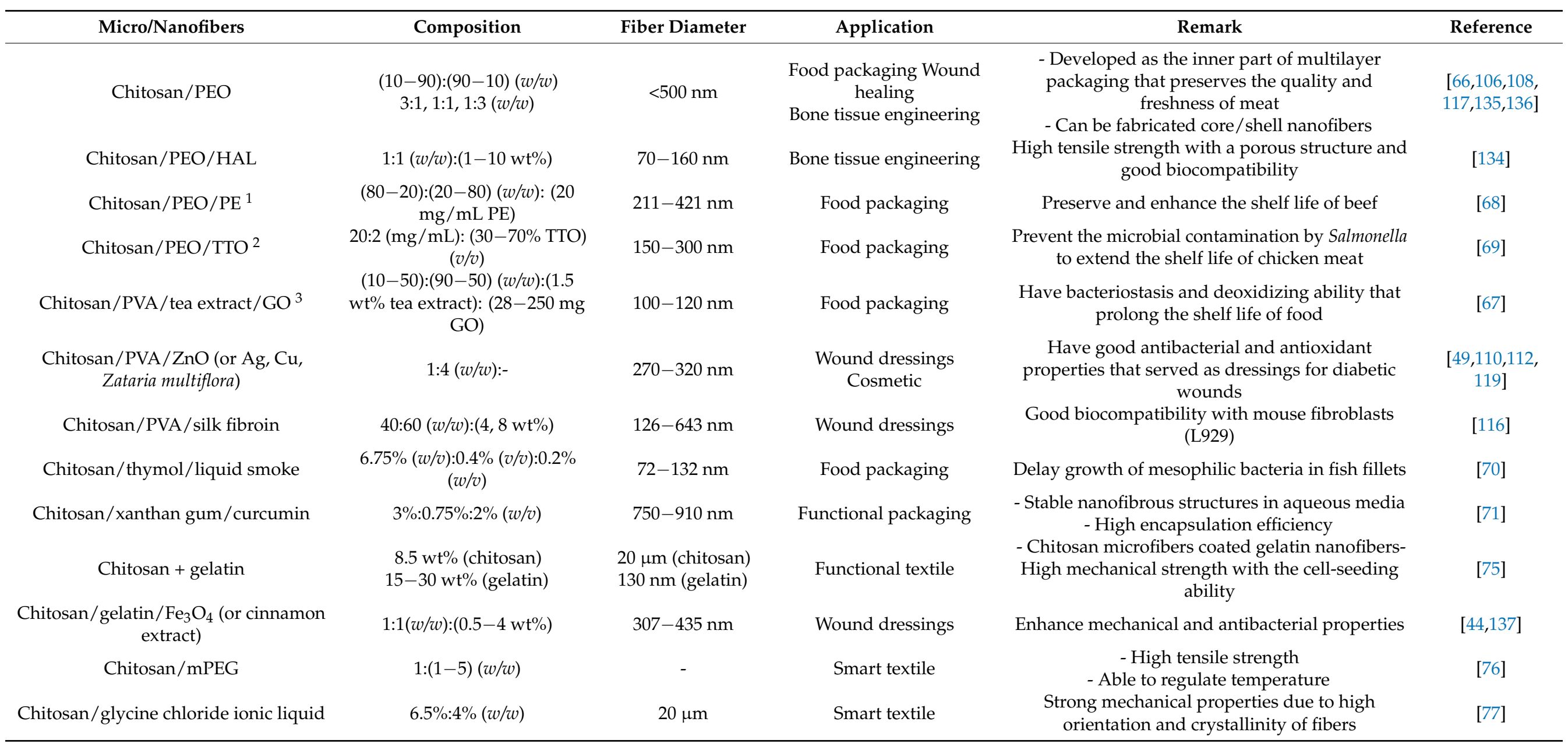


Table 2. Cont

\begin{tabular}{|c|c|c|c|c|c|}
\hline Micro/Nanofibers & Composition & Fiber Diameter & Application & Remark & Reference \\
\hline Chitosan + cotton & $50: 50$ & - & Functional textile & $\begin{array}{l}\text { - High tensile strength } \\
\text { - High uniformity of fiber distribution }\end{array}$ & [80] \\
\hline Chitosan + PAN & $12: 88,30: 70,50: 50$ & - & Functional textile & $\begin{array}{l}\text { - High tenacity } \\
\text { - Reduce electrostatic charges }\end{array}$ & [81] \\
\hline Chitosan/nylon-6 & $3 \%: 21 \%(w / v)$ & $200-350 \mathrm{~nm}$ & Wound healing & Fabricated as core/shell antimicrobial nanofibers & [102] \\
\hline Chitosan/PLA & $50: 50(w / w)$ & $840 \mathrm{~nm}$ & Wound healing & $\begin{array}{l}\text { Suppress the adhesion of bacteria S. aureus and } E . \\
\text { coli }\end{array}$ & {$[104,105]$} \\
\hline Chitosan/PCL/aloe vera & $(1-3):(8-5)(w / w):\left(1-3 w t^{\circ} \%\right)$ & $<100 \mathrm{~nm}$ & $\begin{array}{l}\text { Wound dressings } \\
\text { Cosmetic }\end{array}$ & $\begin{array}{c}\text { High antibacterial performance and } \\
\text { biocompatibility }\end{array}$ & \\
\hline Chitosan/PPC 4 /curcumin & $1: 2(w / w): 10 w t \%$ & $200-400 \mathrm{~nm}$ & Wound healing & Enhance wound healing efficacy & [120] \\
\hline Chitosan/HAp & $70: 30(w / w)$ & $195-240 \mathrm{~nm}$ & Bone tissue engineering & Stimulate the bone forming ability & {$[132,133]$} \\
\hline Chitosan/collagen/PEO/polypyrrole & 2.6:0.6:2.1 (w/v): $\left(5-25 w^{\circ} \%\right)$ & $83-140 \mathrm{~nm}$ & Skin tissue engineering & $\begin{array}{l}\text { Conductive nano-scaffolds with high } \\
\text { biocompatibility }\end{array}$ & [138] \\
\hline
\end{tabular}

${ }^{1}$ PE: pomegranate peel extract, ${ }^{2}$ TTO: tea tree oil liposomes, ${ }^{3}$ GO: glucose oxidase, ${ }^{4}$ PPC: poly (propylene carbonate) 
Author Contributions: This work was conceptualized by H.J.H., S.P.L., and J.J.B., the first draft and literature review were performed by N.D.T., the first revision was performed by H.J.H. and J.J.B., the grant was acquired by S.P.L. and H.J.H., and the final editing and revisions were performed by J.F.M., H.J.H. and S.P.L. All authors have read and agreed to the published version of the manuscript.

Funding: This work was funded by the Research Council of Norwegian (RCN) Nano2021 grant number 287991. This work was also developed within the scope of the project CICECO-Aveiro Institute of Materials, UIDB/50011/2020 \& UIDP/50011/2020, financed by national funds through the Foundation for Science and Technology/MCTES (Portugal).

Institutional Review Board Statement: Not applicable.

Informed Consent Statement: Not applicable.

Conflicts of Interest: The authors declare no conflict of interest.

\section{References}

1. Morin-Crini, N.; Lichtfouse, E.; Torri, G.; Crini, G. Applications of chitosan in food, pharmaceuticals, medicine, cosmetics, agriculture, textiles, pulp and paper, biotechnology, and environmental chemistry. Environ. Chem. Lett. 2019, 17, 1667-1692. [CrossRef]

2. Sahariah, P.; Masson, M. Antimicrobial Chitosan and Chitosan Derivatives: A Review of the Structure-Activity Relationship. Biomacromolecules 2017, 18, 3846-3868. [CrossRef] [PubMed]

3. Rúnarsson, Ö.V.; Holappa, J.; Nevalainen, T.; Hjálmarsdóttir, M.; Järvinen, T.; Loftsson, T.; Einarsson, J.M.; Jónsdóttir, S.; Valdimarsdóttir, M.; Másson, M. Antibacterial activity of methylated chitosan and chitooligomer derivatives: Synthesis and structure activity relationships. Eur. Polym. J. 2007, 43, 2660-2671. [CrossRef]

4. Jones, M.; Kujundzic, M.; John, S.; Bismarck, A. Crab vs. Mushroom: A Review of Crustacean and Fungal Chitin in Wound Treatment. Mar. Drugs 2020, 18, 64. [CrossRef]

5. Kumari, S.; Kishor, R. Chapter 1-Chitin and chitosan: Origin, properties, and applications. In Handbook of Chitin and Chitosan; Gopi, S., Thomas, S., Pius, A., Eds.; Elsevier: Amsterdam, The Netherlands, 2020; pp. 1-33. [CrossRef]

6. Pillai, C.K.S.; Paul, W.; Sharma, C.P. Chitin and chitosan polymers: Chemistry, solubility and fiber formation. Prog. Polym. Sci. 2009, 34, 641-678. [CrossRef]

7. Sashiwa, H.; Aiba, S.-I. Chemically modified chitin and chitosan as biomaterials. Prog. Polym. Sci. 2004, 29, 887-908. [CrossRef]

8. Alves, N.M.; Mano, J.F. Chitosan derivatives obtained by chemical modifications for biomedical and environmental applications. Int. J. Biol. Macromol. 2008, 43, 401-414. [CrossRef]

9. Vunain, E.; Mishra, A.K.; Mamba, B.B. 1-Fundamentals of chitosan for biomedical applications. In Chitosan Based Biomaterials; Jennings, J.A., Bumgardner, J.D., Eds.; Woodhead Publishing: Sawston, UK, 2017; Volume 1, pp. 3-30. [CrossRef]

10. Chatelet, C.; Damour, O.; Domard, A. Influence of the degree of acetylation on some biological properties of chitosan films. Biomaterials 2001, 22, 261-268. [CrossRef]

11. Wenling, C.; Duohui, J.; Jiamou, L.; Yandao, G.; Nanming, Z.; Xiufang, Z. Effects of the degree of deacetylation on the physicochemical properties and Schwann cell affinity of chitosan films. J. Biomater. Appl. 2005, 20, 157-177. [CrossRef]

12. Másson, M. Chitin and chitosan. In Handbook of Hydrocolloids; Elsevier: Amsterdam, The Netherlands, 2021 ; pp. $1039-1072$.

13. Sukul, M.; Sahariah, P.; Lauzon, H.L.; Borges, J.; Másson, M.; Mano, J.F.; Haugen, H.J.; Reseland, J.E. In vitro biological response of human osteoblasts in 3D chitosan sponges with controlled degree of deacetylation and molecular weight. Carbohydr. Polym. 2021, 254, 117434. [CrossRef] [PubMed]

14. Foster, L.J.R.; Ho, S.; Hook, J.; Basuki, M.; Marçal, H. Chitosan as a Biomaterial: Influence of Degree of Deacetylation on Its Physiochemical, Material and Biological Properties. PLOS ONE 2015, 10, e0135153. [CrossRef] [PubMed]

15. Zhou, X.; Kong, M.; Cheng, X.J.; Feng, C.; Li, J.; Li, J.J.; Chen, X.G. In vitro and in vivo evaluation of chitosan microspheres with different deacetylation degree as potential embolic agent. Carbohydr. Polym. 2014, 113, 304-313. [CrossRef]

16. Sahariah, P.; Gaware, V.S.; Lieder, R.; Jonsdottir, S.; Hjalmarsdottir, M.A.; Sigurjonsson, O.E.; Masson, M. The effect of substituent, degree of acetylation and positioning of the cationic charge on the antibacterial activity of quaternary chitosan derivatives. Mar. Drugs 2014, 12, 4635-4658. [CrossRef] [PubMed]

17. Holappa, J.; Hjalmarsdottir, M.; Masson, M.; Runarsson, O.; Asplund, T.; Soininen, P.; Nevalainen, T.; Jarvinen, T. Antimicrobial activity of chitosan N-betainates. Carbohydr. Polym. 2006, 65, 114-118. [CrossRef]

18. Kong, M.; Chen, X.G.; Xing, K.; Park, H.J. Antimicrobial properties of chitosan and mode of action: A state of the art review. Int. J. Food Microbiol. 2010, 144, 51-63. [CrossRef]

19. Zhang, H.; Neau, S.H. In vitro degradation of chitosan by a commercial enzyme preparation: Effect of molecular weight and degree of deacetylation. Biomaterials 2001, 22, 1653-1658. [CrossRef]

20. Rahmati, M.; Silva, E.A.; Reseland, J.E.; Heyward, C.A.; Haugen, H.J.; C. Biological responses to physicochemical properties of biomaterial surface. Chem. Soc. Rev. 2020, 49, 5178-5224. [CrossRef]

21. Xue, J.; Wu, T.; Dai, Y.; Xia, Y. Electrospinning and Electrospun Nanofibers: Methods, Materials, and Applications. Chem. Rev. 2019, 119, 5298-5415. [CrossRef] 
22. Han, J.; Xiong, L.; Jiang, X.; Yuan, X.; Zhao, Y.; Yang, D. Bio-functional electrospun nanomaterials: From topology design to biological applications. Prog. Polym. Sci. 2019, 91, 1-28. [CrossRef]

23. Wannatong, L.; Sirivat, A.; Supaphol, P. Effects of solvents on electrospun polymeric fibers: Preliminary study on polystyrene. Polym. Int. 2004, 53, 1851-1859. [CrossRef]

24. Reneker, D.H.; Yarin, A.L. Electrospinning jets and polymer nanofibers. Polymer 2008, 49, 2387-2425. [CrossRef]

25. Luo, C.J.; Nangrejo, M.; Edirisinghe, M. A novel method of selecting solvents for polymer electrospinning. Polymer 2010, 51, 1654-1662. [CrossRef]

26. Lu, P.; Xia, Y. Maneuvering the Internal Porosity and Surface Morphology of Electrospun Polystyrene Yarns by Controlling the Solvent and Relative Humidity. Langmuir 2013, 29, 7070-7078. [CrossRef] [PubMed]

27. Persano, L.; Camposeo, A.; Tekmen, C.; Pisignano, D. Industrial Upscaling of Electrospinning and Applications of Polymer Nanofibers: A Review. Macromol. Mater. Eng. 2013, 298, 504-520. [CrossRef]

28. Montolio, S.; Abarca, G.; Porcar, R.; Dupont, J.; Burguete, M.I.; García-Verdugo, E.; Luis, S.V. Hierarchically structured polymeric ionic liquids and polyvinylpyrrolidone mat-fibers fabricated by electrospinning. J. Mater. Chem. A 2017, 5, 9733-9744. [CrossRef]

29. Tien, N.D.; Maurya, A.K.; Fortunato, G.; Rottmar, M.; Zboray, R.; Erni, R.; Dommann, A.; Rossi, R.M.; Neels, A.; Sadeghpour, A. Responsive Nanofibers with Embedded Hierarchical Lipid Self-Assemblies. Langmuir 2020, 36, 11787-11797. [CrossRef] [PubMed]

30. Li, Z.; Mei, S.; Dong, Y.; She, F.; Kong, L. High Efficiency Fabrication of Chitosan Composite Nanofibers with Uniform Morphology via Centrifugal Spinning. Polymers 2019, 11, 1550. [CrossRef] [PubMed]

31. Mishra, R.; Militky, J.; Venkataraman, M. Electrospun nanofibers. In Nanotechnology in Textiles; Woodhead Publishing: Sawston, UK, 2019; pp. 35-161. [CrossRef]

32. Partheniadis, I.; Nikolakakis, I.; Laidmäe, I.; Heinämäki, J. A Mini-Review: Needleless Electrospinning of Nanofibers for Pharmaceutical and Biomedical Applications. Processes 2020, 8, 673. [CrossRef]

33. Daristotle, J.L.; Behrens, A.M.; Sandler, A.D.; Kofinas, P. A Review of the Fundamental Principles and Applications of Solution Blow Spinning. ACS Appl. Mater. Interfaces 2016, 8, 34951-34963. [CrossRef]

34. Um, I.C.; Fang, D.; Hsiao, B.S.; Okamoto, A.; Chu, B. Electro-Spinning and Electro-Blowing of Hyaluronic Acid. Biomacromolecules 2004, 5, 1428-1436. [CrossRef]

35. Geng, X.; Kwon, O.-H.; Jang, J. Electrospinning of chitosan dissolved in concentrated acetic acid solution. Biomaterials 2005, 26, 5427-5432. [CrossRef]

36. De Vrieze, S.; Westbroek, P.; Van Camp, T.; Van Langenhove, L. Electrospinning of chitosan nanofibrous structures: Feasibility study. J. Mater. Sci. 2007, 42, 8029-8034. [CrossRef]

37. Neamnark, A.; Rujiravanit, R.; Supaphol, P. Electrospinning of hexanoyl chitosan. Carbohydr. Polym. 2006, 66, 298-305. [CrossRef]

38. Vijayan, A.; Sabareeswaran, A.; Kumar, G.V. PEG grafted chitosan scaffold for dual growth factor delivery for enhanced wound healing. Sci. Rep. 2019, 9, 19165. [CrossRef] [PubMed]

39. Alipour, S.M.; Nouri, M.; Mokhtari, J.; Bahrami, S.H. Electrospinning of poly(vinyl alcohol)-water-soluble quaternized chitosan derivative blend. Carbohydr. Res. 2009, 344, 2496-2501. [CrossRef] [PubMed]

40. Ignatova, M.; Manolova, N.; Rashkov, I. Novel antibacterial fibers of quaternized chitosan and poly(vinyl pyrrolidone) prepared by electrospinning. Eur. Polym. J. 2007, 43, 1112-1122. [CrossRef]

41. Abd El-Hack, M.E.; El-Saadony, M.T.; Shafi, M.E.; Zabermawi, N.M.; Arif, M.; Batiha, G.E.; Khafaga, A.F.; Abd El-Hakim, Y.M.; Al-Sagheer, A.A. Antimicrobial and antioxidant properties of chitosan and its derivatives and their applications: A review. Int. J. Biol. Macromol. 2020, 164, 2726-2744. [CrossRef] [PubMed]

42. Shariatinia, Z. Carboxymethyl chitosan: Properties and biomedical applications. Int. J. Biol. Macromol. 2018, 120, 1406-1419. [CrossRef]

43. Chen, Z.G.; Wang, P.W.; Wei, B.; Mo, X.M.; Cui, F.Z. Electrospun collagen-chitosan nanofiber: A biomimetic extracellular matrix for endothelial cell and smooth muscle cell. Acta Biomater. 2010, 6, 372-382. [CrossRef]

44. Cai, N.; Li, C.; Han, C.; Luo, X.; Shen, L.; Xue, Y.; Yu, F. Tailoring mechanical and antibacterial properties of chitosan/gelatin nanofiber membranes with Fe3O4 nanoparticles for potential wound dressing application. Appl. Surf. Sci. 2016, 369, 492-500. [CrossRef]

45. Phan, D.-N.; Lee, H.; Huang, B.; Mukai, Y.; Kim, I.-S. Fabrication of electrospun chitosan/cellulose nanofibers having adsorption property with enhanced mechanical property. Cellulose 2019, 26, 1781-1793. [CrossRef]

46. Bösiger, P.; Richard, I.M.T.; Le Gat, L.; Michen, B.; Schubert, M.; Rossi, R.M.; Fortunato, G. Application of response surface methodology to tailor the surface chemistry of electrospun chitosan-poly(ethylene oxide) fibers. Carbohydr. Polym. 2018, 186, 122-131. [CrossRef] [PubMed]

47. Pakravan, M.; Heuzey, M.-C.; Ajji, A. A fundamental study of chitosan/PEO electrospinning. Polymer 2011, 52, 4813-4824. [CrossRef]

48. Jia, Y.-T.; Gong, J.; Gu, X.-H.; Kim, H.-Y.; Dong, J.; Shen, X.-Y. Fabrication and characterization of poly (vinyl alcohol)/chitosan blend nanofibers produced by electrospinning method. Carbohydr. Polym. 2007, 67, 403-409. [CrossRef]

49. Zou, P.; Lee, W.-H.; Gao, Z.; Qin, D.; Wang, Y.; Liu, J.; Sun, T.; Gao, Y. Wound dressing from polyvinyl alcohol/chitosan electrospun fiber membrane loaded with OH-CATH30 nanoparticles. Carbohydr. Polym. 2020, 232, 115786. [CrossRef] 
50. Van der Schueren, L.; Steyaert, I.; De Schoenmaker, B.; De Clerck, K. Polycaprolactone/chitosan blend nanofibres electrospun from an acetic acid/formic acid solvent system. Carbohydr. Polym. 2012, 88, 1221-1226. [CrossRef]

51. Semnani, D.; Naghashzargar, E.; Hadjianfar, M.; Dehghan Manshadi, F.; Mohammadi, S.; Karbasi, S.; Effaty, F. Evaluation of PCL/chitosan electrospun nanofibers for liver tissue engineering. Int. J. Polym. Mater. Polym. Biomater. 2017, 66, 149-157. [CrossRef]

52. Bienek, D.R.; Hoffman, K.M.; Tutak, W. Blow-spun chitosan/PEG/PLGA nanofibers as a novel tissue engineering scaffold with antibacterial properties. J. Mater. Sci. Mater. Med. 2016, 27, 146. [CrossRef]

53. Ko, J.E.; Ko, Y.-G.; Kim, W.I.; Kwon, O.K.; Kwon, O.H. Nanofiber mats composed of a chitosan-poly(d,l-lactic-co-glycolic acid)-poly(ethylene oxide) blend as a postoperative anti-adhesion agent. J. Biomed. Mater. Res. Part B Appl. Biomater. 2017, 105, 1906-1915. [CrossRef]

54. Mohraz, M.H.; Golbabaei, F.; Yu, I.J.; Mansournia, M.A.; Zadeh, A.S.; Dehghan, S.F. Preparation and optimization of multifunctional electrospun polyurethane/chitosan nanofibers for air pollution control applications. Int. J. Environ. Sci. Technol. 2019, 16, 681-694. [CrossRef]

55. Tebyetekerwa, M.; Xu, Z.; Yang, S.; Ramakrishna, S. Electrospun Nanofibers-Based Face Masks. Adv. Fiber Mater. 2020, 1-6. [CrossRef]

56. Hathout, R.M.; Kassem, D.H. Positively Charged Electroceutical Spun Chitosan Nanofibers Can Protect Health Care Providers From COVID-19 Infection: An Opinion. Front. Bioeng. Biotechnol. 2020, 8, 885. [CrossRef] [PubMed]

57. Indumathi, M.P.; Saral Sarojini, K.; Rajarajeswari, G.R. Antimicrobial and biodegradable chitosan/cellulose acetate phthalate/ZnO nano composite films with optimal oxygen permeability and hydrophobicity for extending the shelf life of black grape fruits. Int. J. Biol. Macromol. 2019, 132, 1112-1120. [CrossRef] [PubMed]

58. Tian, F.; Chen, W.; Wu, C.E.; Kou, X.; Fan, G.; Li, T.; Wu, Z. Preservation of Ginkgo biloba seeds by coating with chitosan/nanoTiO2 and chitosan/nano-SiO2 films. Int. J. Biol. Macromol. 2019, 126, 917-925. [CrossRef] [PubMed]

59. Ferreira, D.C.M.; de Souza, A.L.; da Silveira, J.V.W.; Marim, B.M.; Giraldo, G.A.G.; Mantovan, J.; Mali, S.; Pelissari, F.M. Chapter 17-Chitosan nanocomposites for food packaging applications. In Multifunctional Hybrid Nanomaterials for Sustainable Agri-Food and Ecosystems; Abd-Elsalam, K.A., Ed.; Elsevier: Amsterdam, The Netherlands, 2020; pp. 393-435. [CrossRef]

60. Ramakrishna, S.; Fujihara, K.; Teo, W.-E.; Yong, T.; Ma, Z.; Ramaseshan, R. Electrospun nanofibers: Solving global issues. Mater. Today 2006, 9, 40-50. [CrossRef]

61. Farhoodi, M. Nanocomposite Materials for Food Packaging Applications: Characterization and Safety Evaluation. Food Eng. Rev. 2016, 8, 35-51. [CrossRef]

62. Mousavi Khaneghah, A.; Hashemi, S.M.B.; Limbo, S. Antimicrobial agents and packaging systems in antimicrobial active food packaging: An overview of approaches and interactions. Food Bioprod. Process. 2018, 111, 1-19. [CrossRef]

63. Youssef, A.M.; El-Sayed, S.M. Bionanocomposites materials for food packaging applications: Concepts and future outlook. Carbohydr. Polym. 2018, 193, 19-27. [CrossRef]

64. de Farias, B.S.; Junior, T.R.S.A.C.; de Almeida Pinto, L.A. Chitosan-functionalized nanofibers: A comprehensive review on challenges and prospects for food applications. Int. J. Biol. Macromol. 2019, 123, 210-220. [CrossRef]

65. Ngo, D.-H.; Kim, S.-K. Chapter Two-Antioxidant Effects of Chitin, Chitosan, and Their Derivatives. In Advances in Food and Nutrition Research; Kim, S.-K., Ed.; Academic Press: Cambridge, MA, USA, 2014; Volume 73, pp. 15-31.

66. Arkoun, M.; Daigle, F.; Holley, R.A.; Heuzey, M.C.; Ajji, A. Chitosan-based nanofibers as bioactive meat packaging materials. Packag. Technol. Sci. 2018, 31, 185-195. [CrossRef]

67. Ge, L.; Zhao, Y.-s.; Mo, T.; Li, J.-r.; Li, P. Immobilization of glucose oxidase in electrospun nanofibrous membranes for food preservation. Food Control. 2012, 26, 188-193. [CrossRef]

68. Surendhiran, D.; Li, C.; Cui, H.; Lin, L. Fabrication of high stability active nanofibers encapsulated with pomegranate peel extract using chitosan/PEO for meat preservation. Food Packag. Shelf Life 2020, 23, 100439. [CrossRef]

69. Cui, H.; Bai, M.; Li, C.; Liu, R.; Lin, L. Fabrication of chitosan nanofibers containing tea tree oil liposomes against Salmonella spp. in chicken. LWT 2018, 96, 671-678. [CrossRef]

70. Ceylan, Z.; Unal Sengor, G.F.; Yilmaz, M.T. Nanoencapsulation of liquid smoke/thymol combination in chitosan nanofibers to delay microbiological spoilage of sea bass (Dicentrarchus labrax) fillets. J. Food Eng. 2018, 229, 43-49. [CrossRef]

71. Shekarforoush, E.; Ajalloueian, F.; Zeng, G.; Mendes, A.C.; Chronakis, I.S. Electrospun xanthan gum-chitosan nanofibers as delivery carrier of hydrophobic bioactives. Mater. Lett. 2018, 228, 322-326. [CrossRef]

72. Jayakumar, R.; Prabaharan, M.; Nair, S.V.; Tamura, H. Novel chitin and chitosan nanofibers in biomedical applications. Biotechnol. Adv. 2010, 28, 142-150. [CrossRef]

73. Liu, S.; Sun, G. Bio-functional textiles. In Handbook of Medical Textiles; Bartels, V.T., Ed.; Woodhead Publishing: UK, 2011; pp. 336-359.

74. Alagirusamy, R.; Das, A. Chapter 8-Conversion of Fibre to Yarn: An Overview. In Textiles and Fashion; Sinclair, R., Ed.; Woodhead Publishing: Sawston, UK, 2015; pp. 159-189. [CrossRef]

75. Hild, M.; Toskas, G.; Aibibu, D.; Wittenburg, G.; Meissner, H.; Cherif, C.; Hund, R.-D. Chitosan/gelatin micro/nanofiber 3D composite scaffolds for regenerative medicine. Compos. Interfaces 2014, 21, 301-308. [CrossRef]

76. Bao, D.; Liu, L.; Sun, T.; Han, Y.; Meng, F.; Zhao, M.; Yu, Y.; Guo, J.; Zhang, S. Solid solid phase change (SSPC) chitosan-g-mPEG fiber with improved mechanical performance via in-situ wet spinning process. Carbohydr. Polym. 2020, 240, 116313. [CrossRef] 
77. Li, L.; Yuan, B.; Liu, S.; Yu, S.; Xie, C.; Liu, F.; Guo, X.; Pei, L.; Zhang, B. Preparation of high strength chitosan fibers by using ionic liquid as spinning solution. J. Mater. Chem. 2012, 22, 8585-8593. [CrossRef]

78. Wawro, D.; Skrzetuska, E.; Włodarczyk, B.; Kowalski, K.; Krucińska, I. Processing of Chitosan Yarn into Knitted Fabrics. Fibres Text. East. Eur. 2016, 120, 52-57. [CrossRef]

79. Zhu, K.; Wang, Y.; Lu, A.; Fu, Q.; Hu, J.; Zhang, L. Cellulose/Chitosan Composite Multifilament Fibers with Two-Switch Shape Memory Performance. ACS Sustain. Chem. Eng. 2019, 7, 6981-6990. [CrossRef]

80. Lam, N.Y.K.; Zhang, M.; Guo, H.-f.; Ho, C.P.; Li, L. Effect of fiber length and blending method on the tensile properties of ring spun chitosan-cotton blend yarns. Text. Res. J. 2016, 87, 244-257. [CrossRef]

81. Liu, S.; Hua, T.; Luo, X.; Yi Lam, N.; Tao, X.-m.; Li, L. A novel approach to improving the quality of chitosan blended yarns using static theory. Text. Res. J. 2014, 85, 1022-1034. [CrossRef]

82. Mülhaupt, R. Green polymer chemistry and bio-based plastics: Dreams and reality. Macromol. Chem. Phys. 2013, 214, 159-174. [CrossRef]

83. Shahid ul, I.; Butola, B.S. Recent advances in chitosan polysaccharide and its derivatives in antimicrobial modification of textile materials. Int. J. Biol. Macromol. 2019, 121, 905-912. [CrossRef]

84. Shamshina, J.L.; Berton, P.; Rogers, R.D. Advances in Functional Chitin Materials: A Review. ACS Sustain. Chem. Eng. 2019, 7, 6444-6457. [CrossRef]

85. Mieszko, W.; Klaus, W.B.; Natalia, G.; Anna, P.-S. Clinical Application of Chitosan in Dental Specialities. Mini-Rev. Med. Chem. 2017, 17, 401-409. [CrossRef]

86. Aranaz, I.; Acosta, N.; Civera, C.; Elorza, B.; Mingo, J.; Castro, C.; Gandía, M.D.; Heras Caballero, A. Cosmetics and Cosmeceutical Applications of Chitin, Chitosan and Their Derivatives. Polymers 2018, 10, 213. [CrossRef] [PubMed]

87. Afonso, C.R.; Hirano, R.S.; Gaspar, A.L.; Chagas, E.G.L.; Carvalho, R.A.; Silva, F.V.; Leonardi, G.R.; Lopes, P.S.; Silva, C.F.; Yoshida, C.M.P. Biodegradable antioxidant chitosan films useful as an anti-aging skin mask. Int. J. Biol. Macromol. 2019, 132, 1262-1273. [CrossRef]

88. Kong, C.-S.; Kim, J.-A.; Ahn, B.; Byun, H.-G.; Kim, S.-K. Carboxymethylations of chitosan and chitin inhibit MMP expression and ROS scavenging in human fibrosarcoma cells. Process. Biochem. 2010, 45, 179-186. [CrossRef]

89. Costa, E.M.; Silva, S.; Madureira, A.R.; Cardelle-Cobas, A.; Tavaria, F.K.; Pintado, M.M. A comprehensive study into the impact of a chitosan mouthwash upon oral microorganism's biofilm formation in vitro. Carbohydr. Polym. 2014, 101, 1081-1086. [CrossRef]

90. Resende, A.H.M.; Farias, J.M.; Silva, D.D.B.; Rufino, R.D.; Luna, J.M.; Stamford, T.C.M.; Sarubbo, L.A. Application of biosurfactants and chitosan in toothpaste formulation. Colloids Surf. B Biointerfaces 2019, 181, 77-84. [CrossRef] [PubMed]

91. Sionkowska, A.; Kaczmarek, B.; Michalska, M.; Lewandowska, K.; Grabska, S. Preparation and characterization of collagen/chitosan/hyaluronic acid thin films for application in hair care cosmetics. Pure Appl. Chem. 2017, 89, 1829-1839. [CrossRef]

92. Morganti, P.; Del Ciotto, P.; Carezzi, F.; Nunziata, M.L.; Morganti, G. A chitin nanofibril-based non-woven tissue as medical dressing: The role of bionanotechnology. Nanomater. Regen. Med. 2016, 1, 123-142.

93. Malette, W.G.; Quigley, H.J.; Gaines, R.D.; Johnson, N.D.; Rainer, W.G. Chitosan: A New Hemostatic. Ann. Thorac. Surg. 1983, 36, 55-58. [CrossRef]

94. Augustine, R.; Rehman, S.R.U.; Ahmed, R.; Zahid, A.A.; Sharifi, M.; Falahati, M.; Hasan, A. Electrospun chitosan membranes containing bioactive and therapeutic agents for enhanced wound healing. Int. J. Biol. Macromol. 2020, 156, 153-170. [CrossRef]

95. Gosain, A.; DiPietro, L.A. Aging and Wound Healing. World J. Surg. 2004, 28, 321-326. [CrossRef]

96. Boateng, J.S.; Matthews, K.H.; Stevens, H.N.E.; Eccleston, G.M. Wound Healing Dressings and Drug Delivery Systems: A Review. J. Pharm. Sci. 2008, 97, 2892-2923. [CrossRef]

97. Patrulea, V.; Ostafe, V.; Borchard, G.; Jordan, O. Chitosan as a starting material for wound healing applications. Eur. J. Pharm. Biopharm. 2015, 97, 417-426. [CrossRef]

98. Antunes, B.P.; Moreira, A.F.; Gaspar, V.M.; Correia, I.J. Chitosan/arginine-chitosan polymer blends for assembly of nanofibrous membranes for wound regeneration. Carbohydr. Polym. 2015, 130, 104-112. [CrossRef]

99. Memic, A.; Abudula, T.; Mohammed, H.S.; Joshi Navare, K.; Colombani, T.; Bencherif, S.A. Latest Progress in Electrospun Nanofibers for Wound Healing Applications. ACS Appl. Bio Mater. 2019, 2, 952-969. [CrossRef]

100. Homaeigohar, S.; Boccaccini, A.R. Antibacterial biohybrid nanofibers for wound dressings. Acta Biomater. 2020, 107, 25-49. [CrossRef] [PubMed]

101. Simões, D.; Miguel, S.P.; Ribeiro, M.P.; Coutinho, P.; Mendonça, A.G.; Correia, I.J. Recent advances on antimicrobial wound dressing: A review. Eur. J. Pharm. Biopharm. 2018, 127, 130-141. [CrossRef]

102. Keirouz, A.; Radacsi, N.; Ren, Q.; Dommann, A.; Beldi, G.; Maniura-Weber, K.; Rossi, R.M.; Fortunato, G. Nylon-6/chitosan core/shell antimicrobial nanofibers for the prevention of mesh-associated surgical site infection. J. Nanobiotechnol. 2020, 18, 51. [CrossRef] [PubMed]

103. Al-Musawi, S.; Albukhaty, S.; Al-Karagoly, H.; Sulaiman, G.M.; Alwahibi, M.S.; Dewir, Y.H.; Soliman, D.A.; Rizwana, H. Antibacterial Activity of Honey/Chitosan Nanofibers Loaded with Capsaicin and Gold Nanoparticles for Wound Dressing. Molecules 2020, 25, 4770. [CrossRef] [PubMed]

104. Ignatova, M.; Manolova, N.; Markova, N.; Rashkov, I. Electrospun Non-Woven Nanofibrous Hybrid Mats Based on Chitosan and PLA for Wound-Dressing Applications. Macromol. Biosci. 2009, 9, 102-111. [CrossRef] [PubMed] 
105. Li, Y.; Chen, F.; Nie, J.; Yang, D. Electrospun poly(lactic acid)/chitosan core-shell structure nanofibers from homogeneous solution. Carbohydr. Polym. 2012, 90, 1445-1451. [CrossRef] [PubMed]

106. Zhang, J.-F.; Yang, D.-Z.; Xu, F.; Zhang, Z.-P.; Yin, R.-X.; Nie, J. Electrospun Core-Shell Structure Nanofibers from Homogeneous Solution of Poly(ethylene oxide)/Chitosan. Macromolecules 2009, 42, 5278-5284. [CrossRef]

107. Yin, J.; Xu, L. Batch preparation of electrospun polycaprolactone/chitosan/aloe vera blended nanofiber membranes for novel wound dressing. Int. J. Biol. Macromol. 2020, 160, 352-363. [CrossRef]

108. Trinca, R.B.; Westin, C.B.; da Silva, J.A.F.; Moraes, Â.M. Electrospun multilayer chitosan scaffolds as potential wound dressings for skin lesions. Eur. Polym. J. 2017, 88, 161-170. [CrossRef]

109. Zhou, X.; Wang, H.; Zhang, J.; Li, X.; Wu, Y.; Wei, Y.; Ji, S.; Kong, D.; Zhao, Q. Functional poly( $\varepsilon$-caprolactone)/chitosan dressings with nitric oxide-releasing property improve wound healing. Acta Biomater. 2017, 54, 128-137. [CrossRef]

110. Ahmed, R.; Tariq, M.; Ali, I.; Asghar, R.; Noorunnisa Khanam, P.; Augustine, R.; Hasan, A. Novel electrospun chitosan/polyvinyl alcohol/zinc oxide nanofibrous mats with antibacterial and antioxidant properties for diabetic wound healing. Int. J. Biol. Macromol. 2018, 120, 385-393. [CrossRef]

111. Archana, D.; Dutta, J.; Dutta, P.K. Evaluation of chitosan nano dressing for wound healing: Characterization, in vitro and in vivo studies. Int. J. Biol. Macromol. 2013, 57, 193-203. [CrossRef] [PubMed]

112. Kharaghani, D.; Khan, M.Q.; Tamada, Y.; Ogasawara, H.; Inoue, Y.; Saito, Y.; Hashmi, M.; Kim, I.S. Fabrication of electrospun antibacterial PVA/Cs nanofibers loaded with CuNPs and AgNPs by an in-situ method. Polym. Test. 2018, 72, 315-321. [CrossRef]

113. Lansdown, A.; Williams, A. How safe is silver in wound care? J. Wound Care 2004, 13, 131-136. [CrossRef] [PubMed]

114. Borkow, G.; Okon-Levy, N.; Gabbay, J. Copper oxide impregnated wound dressing: Biocidal and safety studies. Wounds 2010, 22, 301-310. [PubMed]

115. Lin, T.-C.; Lin, F.-H.; Lin, J.-C. In vitro feasibility study of the use of a magnetic electrospun chitosan nanofiber composite for hyperthermia treatment of tumor cells. Acta Biomater. 2012, 8, 2704-2711. [CrossRef]

116. Zhou, Y.; Yang, H.; Liu, X.; Mao, J.; Gu, S.; Xu, W. Electrospinning of carboxyethyl chitosan/poly(vinyl alcohol)/silk fibroin nanoparticles for wound dressings. Int. J. Biol. Macromol. 2013, 53, 88-92. [CrossRef] [PubMed]

117. Xie, Z.; Paras, C.B.; Weng, H.; Punnakitikashem, P.; Su, L.-C.; Vu, K.; Tang, L.; Yang, J.; Nguyen, K.T. Dual growth factor releasing multi-functional nanofibers for wound healing. Acta Biomater. 2013, 9, 9351-9359. [CrossRef]

118. Bayat, S.; Amiri, N.; Pishavar, E.; Kalalinia, F.; Movaffagh, J.; Hashemi, M. Bromelain-loaded chitosan nanofibers prepared by electrospinning method for burn wound healing in animal models. Life Sci. 2019, 229, 57-66. [CrossRef]

119. Ardekani, N.T.; Khorram, M.; Zomorodian, K.; Yazdanpanah, S.; Veisi, H.; Veisi, H. Evaluation of electrospun poly (vinyl alcohol)based nanofiber mats incorporated with Zataria multiflora essential oil as potential wound dressing. Int. J. Biol. Macromol. 2019, 125, 743-750. [CrossRef] [PubMed]

120. Mei, L.; Fan, R.; Li, X.; Wang, Y.; Han, B.; Gu, Y.; Zhou, L.; Zheng, Y.; Tong, A.; Guo, G. Nanofibers for improving the wound repair process: The combination of a grafted chitosan and an antioxidant agent. Polym. Chem. 2017, 8, 1664-1671. [CrossRef]

121. Yao, C.-H.; Chen, K.-Y.; Chen, Y.-S.; Li, S.-J.; Huang, C.-H. Lithospermi radix extract-containing bilayer nanofiber scaffold for promoting wound healing in a rat model. Mater. Sci. Eng. C 2019, 96, 850-858. [CrossRef] [PubMed]

122. Santos, L.F.; Correia, I.J.; Silva, A.S.; Mano, J.F. Biomaterials for drug delivery patches. Eur J. Pharm. Sci. 2018, 118, 49-66. [CrossRef] [PubMed]

123. Duval, K.; Grover, H.; Han, L.H.; Mou, Y.; Pegoraro, A.F.; Fredberg, J.; Chen, Z. Modeling Physiological Events in 2D vs. 3D Cell Culture. Physiology 2017, 32, 266-277. [CrossRef] [PubMed]

124. MacNeil, S. Biomaterials for tissue engineering of skin. Mater. Today 2008, 11, 26-35. [CrossRef]

125. Pereira, R.F.; Barrias, C.C.; Granja, P.L.; Bartolo, P.J. Advanced biofabrication strategies for skin regeneration and repair. Nanomedicine 2013, 8, 603-621. [CrossRef]

126. Franco, R.A.; Min, Y.-K.; Yang, H.-M.; Lee, B.-T. Fabrication and biocompatibility of novel bilayer scaffold for skin tissue engineering applications. J. Biomater. Appl. 2011, 27, 605-615. [CrossRef]

127. Pan, J.-f.; Liu, N.-h.; Sun, H.; Xu, F. Preparation and Characterization of Electrospun PLCL/Poloxamer Nanofibers and Dextran/Gelatin Hydrogels for Skin Tissue Engineering. PLoS ONE 2014, 9, e112885. [CrossRef] [PubMed]

128. Kim, J.W.; Kim, M.J.; Ki, C.S.; Kim, H.J.; Park, Y.H. Fabrication of bi-layer scaffold of keratin nanofiber and gelatin-methacrylate hydrogel: Implications for skin graft. Int. J. Biol. Macromol. 2017, 105, 541-548. [CrossRef]

129. Bacakova, M.; Pajorova, J.; Broz, A.; Hadraba, D.; Lopot, F.; Zavadakova, A.; Vistejnova, L.; Beno, M.; Kostic, I.; Jencova, V. A two-layer skin construct consisting of a collagen hydrogel reinforced by a fibrin-coated polylactide nanofibrous membrane. Int. J. Nanomed. 2019, 14, 5033. [CrossRef]

130. Levengood, S.L.; Zhang, M. Chitosan-based scaffolds for bone tissue engineering. J. Mater. Chem. B 2014, 2, 3161-3184. [CrossRef] [PubMed]

131. Tao, F.; Cheng, Y.; Shi, X.; Zheng, H.; Du, Y.; Xiang, W.; Deng, H. Applications of chitin and chitosan nanofibers in bone regenerative engineering. Carbohydr. Polym. 2020, 230, 115658. [CrossRef] [PubMed]

132. Zhang, Y.; Venugopal, J.R.; El-Turki, A.; Ramakrishna, S.; Su, B.; Lim, C.T. Electrospun biomimetic nanocomposite nanofibers of hydroxyapatite/chitosan for bone tissue engineering. Biomaterials 2008, 29, 4314-4322. [CrossRef] [PubMed] 
133. Zhang, Y.; Reddy, V.J.; Wong, S.Y.; Li, X.; Su, B.; Ramakrishna, S.; Lim, C.T. Enhanced Biomineralization in Osteoblasts on a Novel Electrospun Biocomposite Nanofibrous Substrate of Hydroxyapatite/Collagen/Chitosan. Tissue Eng. Part A 2010, 16, 1949-1960. [CrossRef]

134. Govindasamy, K.; Dahlan, N.A.; Janarthanan, P.; Goh, K.L.; Chai, S.-P.; Pasbakhsh, P. Electrospun chitosan/polyethylene-oxide (PEO)/halloysites (HAL) membranes for bone regeneration applications. Appl. Clay Sci. 2020, 190, 105601. [CrossRef]

135. Saatchi, A.; Arani, A.R.; Moghanian, A.; Mozafari, M. Cerium-doped bioactive glass-loaded chitosan/polyethylene oxide nanofiber with elevated antibacterial properties as a potential wound dressing. Ceram. Int. 2021, 47, 9447-9461. [CrossRef]

136. Toullec, C.; Le Bideau, J.; Geoffroy, V.; Halgand, B.; Buchtova, N.; Molina-Peña, R.; Garcion, E.; Avril, S.; Sindji, L.; Dube, A.; et al. Curdlan-Chitosan Electrospun Fibers as Potential Scaffolds for Bone Regeneration. Polymers 2021, 13, 526. [CrossRef]

137. Ahmadi, S.; Hivechi, A.; Bahrami, S.H.; Milan, P.B.; Ashraf, S.S. Cinnamon extract loaded electrospun chitosan/gelatin membrane with antibacterial activity. Int. J. Biol. Macromol. 2021, 173, 580-590. [CrossRef]

138. Zarei, M.; Samimi, A.; Khorram, M.; Abdi, M.M.; Golestaneh, S.I. Fabrication and characterization of conductive polypyrrole/chitosan/collagen electrospun nanofiber scaffold for tissue engineering application. Int. J. Biol. Macromol. 2021, 168, 175-186. [CrossRef]

139. Rahmati, M.; Blaker, J.J.; Lyngstadaas, S.P.; Mano, J.F.; Haugen, H.J. Designing multigradient biomaterials for skin regeneration. Mater. Today Adv. 2020, 5, 100051. [CrossRef]

140. Rahman, S.U.; Nagrath, M.; Ponnusamy, S.; Arany, P.R. Nanoscale and Macroscale Scaffolds with Controlled-Release Polymeric Systems for Dental Craniomaxillofacial Tissue Engineering. Materials 2018, 11, 1478. [CrossRef] [PubMed]

141. Du, X.Y.; Li, Q.; Wu, G.; Chen, S. Multifunctional Micro/Nanoscale Fibers Based on Microfluidic Spinning Technology. Adv. Mater. 2019, 31, e1903733. [CrossRef]

142. Cheng, X.; Zhang, Y. Micro/Nanoscale 3D Assembly by Rolling, Folding, Curving, and Buckling Approaches. Adv. Mater. 2019, 31, e1901895. [CrossRef] [PubMed]

143. Ghimbeu, C.M.; Luchnikov, V.A. Hierarchical porous nitrogen-doped carbon beads derived from biosourced chitosan polymer. Micropor. Mesopor. Mat. 2018, 263, 42-52. [CrossRef]

144. Sarkar, S.D.; Farrugia, B.L.; Dargaville, T.R.; Dhara, S. Chitosan-collagen scaffolds with nano/microfibrous architecture for skin tissue engineering. J. Biomed. Mater. Res. A 2013, 101, 3482-3492. [CrossRef]

145. Merchiers, J.; Meurs, W.; Deferme, W.; Peeters, R.; Buntinx, M.; Reddy, N.K. Influence of Polymer Concentration and Nozzle Material on Centrifugal Fiber Spinning. Polymers 2020, 12, 575. [CrossRef]

146. Wang, F.D.; Hu, S.; Jia, Q.X.; Zhang, L.Q. Advances in Electrospinning of Natural Biomaterials for Wound Dressing. J. Nanomater 2020, 2020. [CrossRef]

147. Ma, J.; Wang, Y.; Liu, J. Biomaterials Meet Microfluidics: From Synthesis Technologies to Biological Applications. Micromachines 2017, 8, 255. [CrossRef]

148. EUTCD. Directive 2004/23/EC of the European Parliament and of the Council of 31 March 2004 on Setting Standards of Quality and Safety for the Donation, Procurement, Testing, Processing, Preservation, Storage and Distribution of Human Tissues and Cells. 2004. Available online: https:/ / eur-lex.europa.eu/legal-content/EN/TXT/?uri=LEGISSUM\%3Ac11573 (accessed on 1 May 2021).

149. MDR. Regulation (EU) 2017/745 of The European Parliament and of the Council of 5 April 2017 on Medical Devices. 2017. Available online: http:/ / data.europa.eu/eli/reg/2017/2745/oj (accessed on 1 May 2021).

150. MarketReport. iData Research, Europe Market. Overview for Dental Bone Graft Substitutes and Other Biomaterials 2017-Research and Markets; iData Research, 2017; Available online: https:/ /idataresearch.com/product/dental-bone-graft-substitutes-market/ (accessed on 3 May 2021).

151. Gao, C.; Zhang, L.; Wang, J.; Jin, M.; Tang, Q.; Chen, Z.; Cheng, Y.; Yang, R.; Zhao, G. Electrospun Nanofibers Promote Wound Healing: Theories, Techniques and Perspectives. J. Mater. Chem B 2021, 9, 3106-3130. [CrossRef] 